\title{
Sector eléctrico de Costa Rica: aplicación del Análisis Estructural para definir variables claves de una reforma neoclásica
}

\section{Roberto Jiménez Gómez}

Centro Nacional de Planificación Eléctrica, Instituto Costarricense de Electricidad, (ICE), Sabana Norte, San José, Costa Rica; rjiemenezg@ice.go.cr

Recibido 11-III-2010 Corregido 17-VI-2010 Aceptado 7-VII-2010

\begin{abstract}
Costa Rica's electricity sector: application of structural analysis to define key variables neoclassical reform. I applied an Structural Analysis to identify the variables that have a greater effect on the electrical system of Costa Rica. The procedure identifies current and future variables, and the actors who can influence them, to generate scenarios of a power sector reform. The main variables are: national wholesale market, decoupling degree of electric industry organizations, competition in electricity generation, political influence in decision making, and power generation potential.
\end{abstract}

\section{KEY WORDS}

Electricity sector reform, structural analysis, forecasting, electricity market, electricity prices, competition and planning, electricity generation sources

\begin{abstract}
RESUMEN
Presento una aplicación de la Técnica de Prospectiva y el Análisis Estructural, el cual se emplea para definir las variables claves que inciden en mayor medida en el sistema eléctrico en el marco de un proceso de reforma en Costa Rica. Permite identificar la situación presente y futura de las variables, los actores que pueden incidir en ellas, y generar escenarios posibles de reforma del sector eléctrico. Se establecieron las variables más importantes, según el modelo actual y las que tendrían más relevancia en caso de que se lleve a cabo una reforma de orientación neoclásica. Dentro de las variables que tendrían una mayor relevancia en un sistema eléctrico reformado están: Mercado mayorista nacional, Grado de disociación de las organizaciones del sector eléctrico, Competencia en la generación de electricidad, Influencia política en las decisiones, Potencial de generación eléctrica de Costa Rica.
\end{abstract}

\section{PALABRAS CLAVE}

Reforma sector eléctrico, análisis estructural, mercado eléctrico, precios de la electricidad, competencia y planificación en la generación eléctrica mercados mayoristas de electricidad, fuentes de generación eléctrica.

\section{El sector eléctrico de Costa Rica}

El sistema eléctrico interconectado de Costa Rica es operado por el Centro Nacional de Control de Energía del Instituto Costarricense de Electricidad (ICE) el cual funge como un administrador y planificador de corto plazo, según las necesidades del sistema eléctrico, siendo además el ICE un comprador único y dueño de las líneas de transmisión eléctrica.

El ICE produce y compra energía eléctrica para venderla o usarla en el segmento de distribución de forma directa o bien por medio de las empresas distribuidoras municipales o cooperativas de electrificación rural, cada una de los cuales tiene una zona geográfica asignada, correspondiéndole al ICE las regiones no concesionadas a ninguna empresa y generalmente más alejadas y dispersas. Las tarifas de todos estos servicios son definidas por la ARESEP con base en el principio de servicio al costo.

En este caso el mercado eléctrico regional, sería un potencial comprador o vendedor de electricidad, estando únicamente el ICE facultado para comprar o vender electricidad. Sobre ese tema existen interpretaciones y discrepancias, entre quienes indican que el mercado eléctrico regional crea un mercado en donde pueden existir diversos compradores y vendedores y otras visiones que sos- 
tienen que el país pueda tener según la decisión interna un comprador único.

La rectoría del sector energía recae sobre el MINAE, el cual con base en legislación existente elabora el Plan Nacional de Energía (PNE) que orienta las acciones de los actores, específicamente el Plan de desarrollo eléctrico nacional (PDEN) que busca orientar a largo plazo la expansión del desarrollo eléctrico de generación, transmisión y distribución eléctrica del ICE e integrando los proyectos de desarrollo de otras empresas del sector eléctrico. La planificación del desarrollo es de largo plazo y normativa, recayendo en esta institución, estas actividades, así como la responsabilidad de asegurar el suministro eléctrico.

En el segmento de producción de electricidad es donde se da mayor participación de actores. Se tiene al ICE como actor dominante. En la legislación previa a las leyes 7200 y 7508, no había ningún tipo de limitación para que empresas de diverso tipo pudieran participar, estas leyes restringieron y establecieron estímulos a la generación privada. Las cooperativas y empresas municipales han ido aumentando su interés y participación en el segmento de generación eléctrica.

El transporte de alta tensión han estado a cargo del ICE. Esto no ha generado discusión pues es considerada una actividad monopólica, no obstante con la creación del mercado eléctrico regional deberá someterse a una serie de reglas y procedimientos definidos en el ámbito regional, que modificarán significativamente la forma de operar, los peajes y las disposiciones para la expansión de la red que deberán ir a concurso internacional.

El despacho y la planificación hay división entre los actores sociales relacionados con el sector eléctrico, pues para unos esto se ha realizado de forma adecuada y por parte de un ente público nacional, mientras que tienen recelan la labor del ICE que tiene labores de carácter nacional de planificación y dirección, mientras participa en actividades empresariales al igual que otros actores del sistema eléctrico nacional (Cuadro 1).

El ICE tiene un papel protagónico en el sector, no obstante se han ido incorporando nuevos actores. En la fase de producción se tienen cooperativas, empresas municipales y generadores privados de electricidad. En la fase de distribución de electricidad se tiene la participación igualmente de cooperativas, empresas municipales, la Compañía Nacional de Fuerza y Luz y el ICE cada una con concesión en un determinado territorio, al ICE le corresponde atender a todas las regiones no concesionadas y dispersas del país.

Como puede verse en el caso del sector eléctrico de Costa Rica pese a que se han diseñado algunas políticas tendientes a ajustarse a la visión de los organismos financieros internacionales y las corrientes que han inspirado

CUADRO 1

Organizaciones del subsector eléctrico según actividad o competencia que ejercen.

\begin{tabular}{|c|c|}
\hline Actividad o competencia & Organizaciones participantes \\
\hline $\begin{array}{l}\text { Rectoría y definición de } \\
\text { políticas nacionales }\end{array}$ & $\begin{array}{l}\text { El Poder Ejecutivo por medio del Ministerio de Ambiente y } \\
\text { Energía sustentado en la Dirección Sectorial de Energía }\end{array}$ \\
\hline $\begin{array}{l}\text { Regulación de los servicios } \\
\text { públicos }\end{array}$ & $\begin{array}{l}\text { La Autoridad Reguladora de Servicios Públicos para todas las } \\
\text { fases del subsector eléctrico. }\end{array}$ \\
\hline $\begin{array}{l}\text { Planificación de largo plazo } \\
\text { del subsector eléctrico }\end{array}$ & El ICE basado en el plan nacional de energía del MINAE. \\
\hline $\begin{array}{l}\text { Centro de control y despacho } \\
\text { del SEN }\end{array}$ & El ICE, con base en criterios técnicos de operación del SEN \\
\hline Producción de electricidad & $\begin{array}{l}\text { ICE, Generadores privados, Cooperativas, Empresas } \\
\text { municipales, Cogeneradores }\end{array}$ \\
\hline Transporte de electricidad & ICE \\
\hline Distribución & ICE, Cooperativas, Empresas municipales, CNFL \\
\hline Comercialización & No se realiza \\
\hline
\end{tabular}


reformas en otros países, se ha aplicado una política heterodoxa, la cual ha consistido en términos generales en:

a. Mantener la propiedad pública de las principales empresas (ICE y CNFL).

b. Participación y fortalecimiento de empresas públicas municipales y cooperativas en las fases de producción y distribución de la cadena de valor de los servicios eléctricos.

c. Permitir la participación privada en el segmento de generación eléctrica hasta un $30 \%$, únicamente con fuentes renovables y con precios regulados por la ARESEP (ley 7200) y mediante concursos licitatorios (7508).

d. Un solo comprador a los generadores privados, el ICE.

e. Una planificación de corto, mediano y largo plazo realizada por un ente estatal, responsable del suministro eléctrico, el ICE.

f. La transmisión y el centro de control de energía propiedad y dirigida por el ICE.

g. Mantener al ICE como una empresa verticalmente integrada, es decir que planifica, diseña, construye, opera, transporta y distribuye en el sector eléctrico.

h. Un sistema con precios regulados bajo el principio de servicio al costo (costos más un rédito para el desarrollo del sistema para cubrir la demanda futura).

En la Figura 1 se muestran algunos indicadores del sector eléctrico de Costa Rica.
Para el año 2009 la generación con fuentes renovables del sector eléctrico de Costa Rica fue $94.6 \%$. Por su parte, en los últimos 26 años en promedio la generación con fuentes renovables fue de $95.11 \%$, un indicador que muestra que la planificación normativa y que el sistema regulado en el país ha tenido un buen desempeño (Fig. 2).

El país ha logrado además aumentar la cobertura eléctrica al $99 \%$, un nivel de los más altos, incluso para países desarrollados. Un sistema regulado y sobre todo con la aplicación de la solidaridad social, por medio de las tarifas

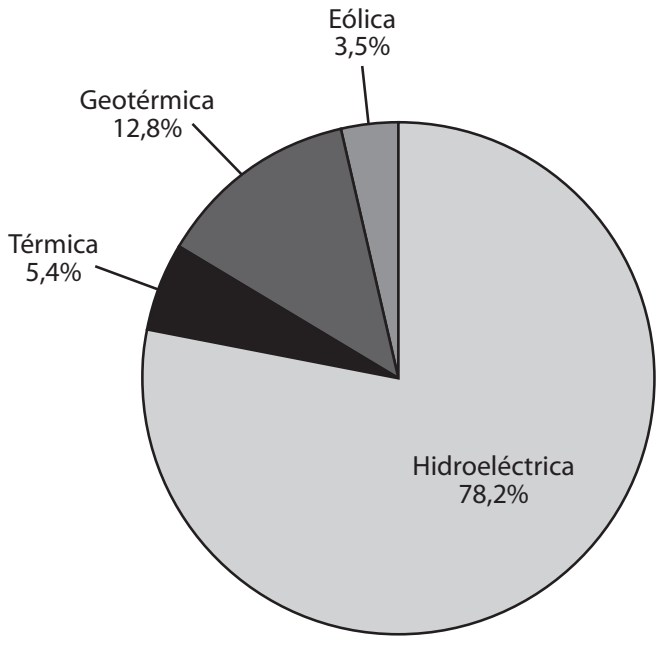

FIG. 1. Distribución porcentual de la generación eléctrica por fuente.

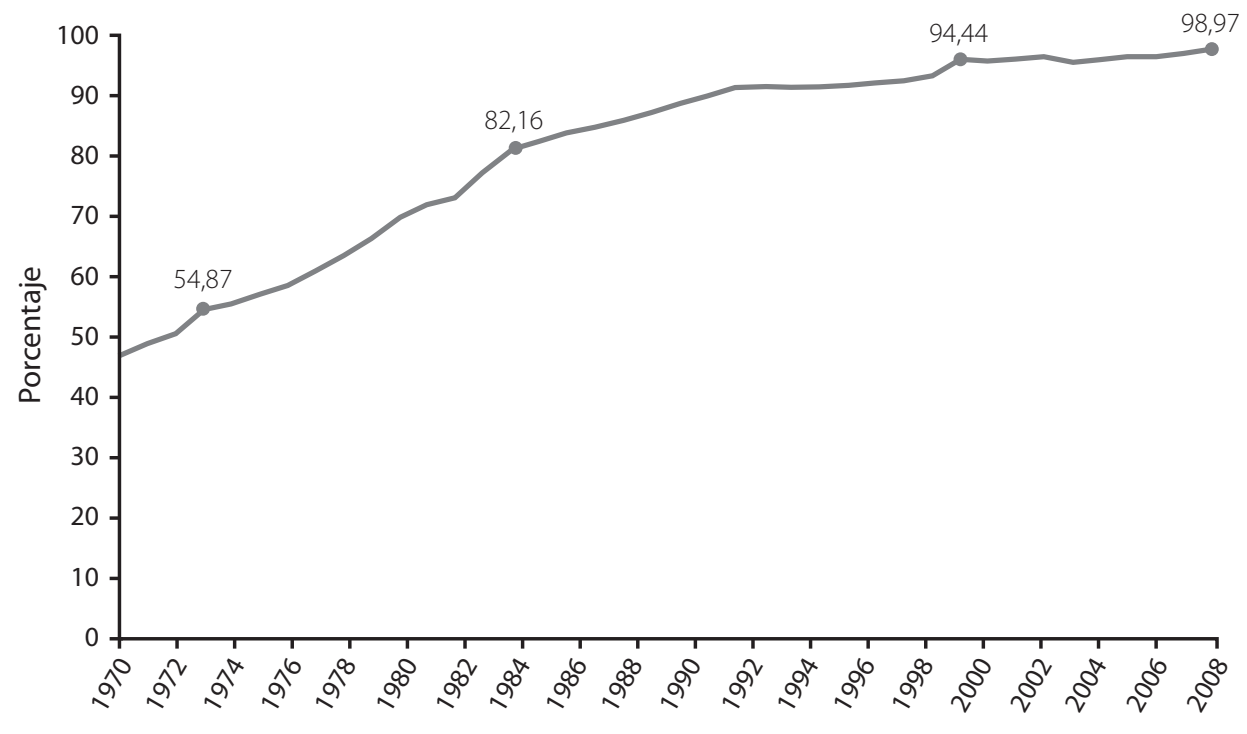

Año

FIG. 2. Evolución de la cobertura eléctrica en Costa Rica. 
entre sectores de consumo ha permitido llegar con el servicio eléctrico a zonas lejas, dispersas y poco rentables financieramente.

Los abonados del sistema eléctrico que consumen menos de $250 \mathrm{KWh}$ tienen que usar un porcentaje relativamente bajo del salario mínimo del país para poder pagar el recibo eléctrico (Fig. 3) . Las tarifas del país en general son competitivas en el ámbito latinoamericano.

Un aspecto importante que tendrá influencia sobre el sector eléctrico del país es el mercado eléctrico de Centro América, pese a que las transacciones originalmente dependan de excedentes, una vez sea cubierta la demanda de cada país, la posibilidad de que se den contratos en un mercado mayorista de corto plazo, crea una nueva dinámica. En el análisis estructural con base en la consideración de algunas variables este aspecto es considerado, lo cual en gran medida lo que hace es profundizar la lógica del mercado, el tamaño y complejidad de éste.

\section{Rasgos fundamentales de las reformas}

En el ámbito internacional en las década de 1980 y 1990, se dan los cambios más importantes tendientes a las transformaciones de los sistemas eléctricos. (Millán 2006) Las reformas en los sistemas eléctricos en el ámbito internacional se han realizado por: (A) Los cambios tecnológicos, que han permitido reducir la escala de las centrales de generación y una mayor competencia, (B) Una revisión de la función reguladora que desempeñan los gobiernos. Estas reformas han consistido de forma general en lo siguiente: (Bazán 2003, Besant 2006, Hunt \& Shuttlesworth 1996)

a. Se da una desintegración vertical entre las actividades potencialmente competitivas (generación y comercialización) y las actividades reguladas (transmisión y distribución) del sector.

b. La introducción de la competencia en la generación y en la comercialización.

c. La creación de mercados eléctricos descentralizados cuya característica fundamental son los mercados eléctricos de contado al por mayor (wholesale electricity spot markets) o pools competitivo.

d. La descentralización de las decisiones de inversión en expansión de la red de transmisión y en capacidad de generación.

e. La regulación de las tarifas y de las condiciones de acceso de terceros a las redes eléctricas (que aún se consideran monopolios naturales).

f. Una redefinición de la regulación (desarrollo de un nuevo marco regulador).

g. Se han realizado privatizaciones en la generación y en la distribución con la esperanza de que inversionistas privados introduzcan recursos financieros en estas fases y con la expectativa de que las empresas busquen reducir sus costos que se lleguen a reflejar en beneficios para el cliente final (Pollitt 2005).

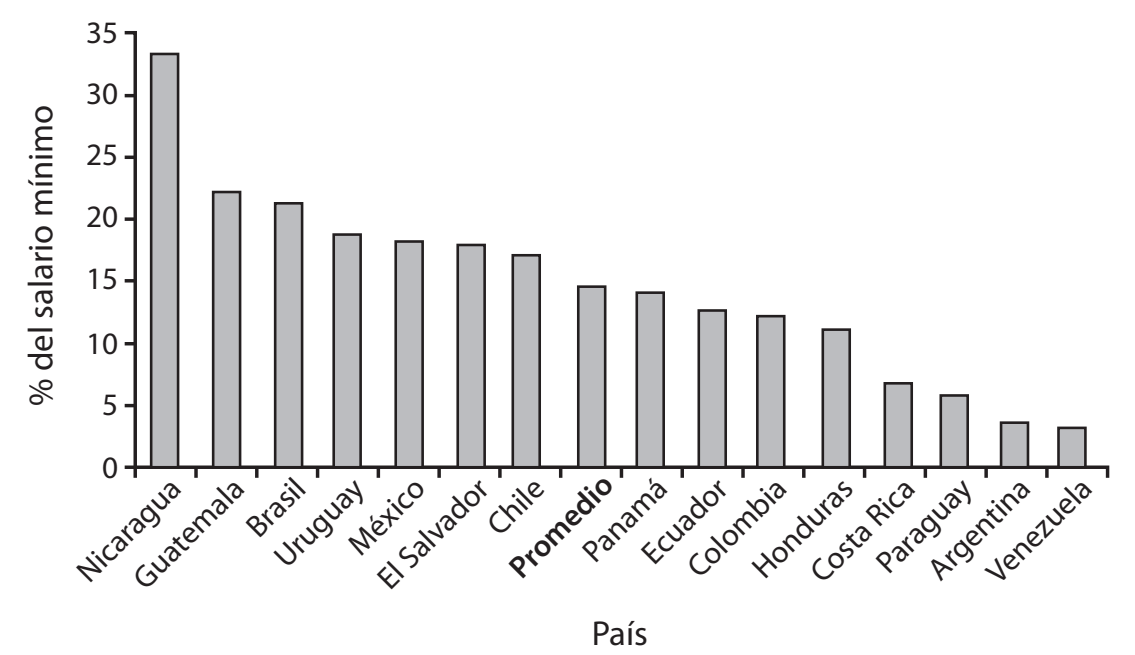

FIG. 3. Porcentaje del salario mínimo que se destina para la adquisición de 250 KWh de energía eléctrica para América Latina. Fuente: OLADE 
De acuerdo con Jamsb (2006) presenta una síntesis de los procesos de reforma realizados en el ámbito internacional. Muestra el camino común que han seguido los procesos de reforma, pasando de la regulación, a leyes de la industria eléctrica, eliminación de las empresas verticalmente integradas, creación de competencia y privatización.

La complejidad de los procesos, la dificultad de creación de mercados que funcionen bien, son elementos que hacen difícil el logro de mayor eficiencia y sobretodo que los usuarios finales vean disminuidas las tarifas.

Principales lecciones de los procesos de reforma:

Dentro de los problemas encontrados según el tipo de diseño de las reformas y la realidad de cada país están los siguientes: (Bacon \& Besants 2001, Besant \& Tenenbaum 2001, Jiménez 2009)

a. Se ha indicado que el mercado eléctrico por sí solo es insuficiente para propiciar las inversiones en proyectos de generación eléctrica con fuentes renovables, situación que enfrentan la mayoría de países que han llevado a cabo procesos de reforma (CEPAL 2004).

b. La solidaridad social hacia los sectores de menos ingresos no se ha dado adecuadamente en los países en donde se han llevado a cabo reformas, lo cual se evidencia por lo general en tarifas elevadas, dificultades de acceso y las zonas que no son rentables no han sido cubiertas (Estache 2002).

c. Estos aspectos plantean un problema serio al proceso de las reformas en el sector eléctrico, lo cual ha sido aún más grave en la mayoría de los países en vías de desarrollo, debido a la falta de capacidad de las organizaciones, no cumplimiento de la normativa e influencia política e intereses económicos en la toma de decisiones (North 2005).

Bazán (2003) \& Millán, (2006) establecen dentro de sus conclusiones los siguientes aspectos:

- Se puede observar que la competencia (imperfecta) entre las empresas eléctricas depende en gran medida de las reglas de acceso a las redes de transmisión y distribución que se adopten tras la reforma, y de que en el sistema no se presenten problemas de congestión, es decir, que el sector cuente con suficiente capacidad para realizar los intercambios de electricidad entre regiones distantes.

- El tamaño del mercado sujeto a la reforma es clave. Mercados potenciales pequeños no permiten el desarrollo de mercados competitivos, además los costos de transacción por la mayor complejidad no compensan las economías de coordinación. Se considera incluso que el mercado de Centroamérica es pequeño.

- Señalan que si se realiza la reforma del sector eléctrico sin cuidar el correcto diseño de los nuevos mecanismos institucionales que gobiernen el acceso a las redes eléctricas y sin adoptar medidas para reducir la elevada concentración heredada del modelo tradicional, no se conseguirá mejorar los resultados del mercado eléctrico respecto del modelo tradicional (Dussán 2004).

- Por otra parte, indican que si tras la reforma del sector eléctrico no existen ganancias de eficiencia productiva (reducción de costos de producción), los consumidores tendrán que pagar precios más altos por la electricidad consumida respecto a los precios del modelo centralizado. No obstante, si la ganancia de eficiencia productiva es lo suficientemente grande, es posible que se produzcan situaciones donde los precios disminuyan tras la reforma del sector (Millán 2006).

En general para que las reformas de mercado en los sistemas eléctricos puedan brindar más beneficios que costos, deben permitir crear mercados competitivos, lo cual está determinado por un conjunto importante de condiciones y características, no fáciles de lograr. Si un sistema eléctrico reformado no puede lograr sistemas competitivos que estimulen fuertemente la eficiencia, es posible que no compensen los beneficios de los sistemas verticalmente integrados y planificados normativamente, como el sistema eléctrico de Costa Rica (Millán 2006).

En el caso de Costa Rica los actores sociales promotores de la reforma neoclásica buscan mayor participación privada en el sector eléctrico: desarrollo de proyectos o comparar empresas que se privaticen en una segunda etapa de la reforma. Además buscan contar con las posibilidades de que los grandes consumidores puedan participar en los mercados para obtener mejores precios, buscan además no subsidiar al sector de consumo residencial. Otros actores desean ser agentes comercializadores para aprovechar oportunidades de negocios en Centroamérica.

\section{La prospectiva}

Para Godet (2007), la prospectiva consiste en concebir un futuro deseado así como los medios necesarios para alcanzarlos. Es la forma en donde el sueño fecunda la realidad, donde el deseo y la intencionalidad es fuente productora del futuro, donde la anticipación ilumina la preactividad y la proactividad.

Según, Mojica (2006) el proceso de análisis prospectivo tiene una serie de etapas fundamentales:

a. Por una parte se parte del análisis del papel de los actores sociales con respecto a los temas centrales o 
aspectos sustantivos del objeto de estudio. Con base en ello es necesario establecer la forma como los actores sociales se comportan con relación al objeto de estudio, determinando cómo están operando los actores sociales.

b. Se elaboran los escenarios de futuro con base en las variables relevantes, estableciendo para dónde se desea orientar la reforma, qué otras situaciones se pueden examinar, así como estableciendo la opción más conveniente.

c. Se debe trabajar en las estrategias, estableciendo qué se debe hacer para construir nuestra mejor opción de futuro, determinando los objetivos y metas que se deberían alcanzar y mediante qué tipo de acciones.

El enfoque de la prospectiva es un campo en evolución, de intersección entre los estudios del futuro, el análisis de políticas públicas y la planificación. Busca aclarar las prioridades gubernamentales y de una región, sector o cadena productiva bajo estudio (Medina \& Ortegón 2006).

En la actualidad sigue vigente la visión clásica de la prospectiva, entendida como anticipación, orientada a la exploración de futuros posibles para clarificar decisiones y acciones presentes. No obstante, la prospectiva de nueva generación añade el concepto de construcción social del futuro, es decir la participación de los actores, sectores o territorios relacionados con el tema en cuestión (Medina \& Ortegón 2006).

Para Mojica (2006) la intención de la prospectiva no es contemplar el futuro si no tratar de incidir para que se logre de la mejor forma. Ante ello no se interesa en medir y observar el fenómeno, pero sí de interpretarlo al interior del campo de los hechos posibles y dentro de una percepción hermenéutica de la realidad.

La prospectiva es una disciplina para el análisis de sistemas sociales, que permite conocer mejor la situación presente e identificar tendencias futuras en la sociedad. Es establecer las necesidades presentes y futuras, así como los posibles efectos y caminos alternativos que puede tener una sociedad.

\section{METODOLOGÍA}

\section{El análisis estructural}

Es una herramienta de estructura de reflexión colectiva. Brinda la posibilidad de describir un sistema con ayuda de una matriz que relaciona todos sus elementos constitutivos (al menos los más significativos o relevantes) (Godet 2007).
El método tiene como objetivo obtener las principales variables influyentes y dependientes, por ello las variables esenciales que explican el sistema eléctrico actual y ante la posibilidad de una reforma neoclásica basada en la creación de un mercado mayorista.

Para ello se seleccionaron y definieron preliminarmente variables, con base en un proceso de análisis de sensibilidad realizado en el programa Excel y la retroalimentación de profesionales del sector eléctrico, se procedió a depurar el conjunto de variables internas y externas que fueron finalmente elegidas como las variables más relevantes.

El análisis estructural permite establecer las relaciones de fuerza y dependencia entre las variables, estableciendo los factores de cambio que se dan en ellas que forman el sistema construido. Con base en ello se determinan las variables más relevantes para el proceso de reforma. El resultado anterior permite establecer cuáles actores sociales tienen mayor incidencia sobre la dinámica de éstas, apoyando al proceso de selección de los actores claves de la red.

A continuación se presenta una aplicación de la técnica denominada análisis estructural que fue desarrollada por Jiménez (2009), para el proceso de reforma del sector eléctrico en Costa Rica.

\section{Aplicación al proceso de reforma del sector eléctrico de Costa Rica}

El presente trabajo establece mediante el análisis estructural las variables más importantes que tiene el sistema eléctrico de Costa Rica en la actualidad y las que tendría en el marco de un proceso de reforma de orientación neoclásica.

El estudio es importante para establecer los posibles efectos, escenarios posibles y determinar las opciones de modelo eléctrico a partir de alternativas de reforma.

Con base en el análisis estructural se procede a seleccionar las variables relevantes, definirlas, estableciendo su importancia para el sector eléctrico. Se establece la importancia actual y futura, así como el dominio presente y grado de desarrollo futuro para gestionar cada una de las variables.

Empleando hojas electrónicas y un programa computacional se hacen una serie de estimaciones por medio de álgebra matricial, que permitió establecer la importancia, dependencia e influencia del sistema matricial, lo cual sirve de base para establecer las variables que puedan asumir más relevancia, en un escenario futuro de cambio de modelo eléctrico basado en el uso del mercado. 
Del análisis realizado se estableció que hay un cambio en la importancia de las variables que se explica por la nueva lógica que asumiría el sector eléctrico reformado. Las variables económicas tales como: el mercado mayorista, criterios para la toma decisiones de inversión, asumen un importante papel, sin embargo, se mantienen variables con relevancia, como la influencia política en la toma de decisiones y la movilización social, como aspectos que pueden incidir en la definición del modelo y en la operación misma del sector reformado.

Para realizar la aplicación del método de prospectiva se siguieron las fases generales:

a. Listado y conceptualización de variables: Listar todas las variables que caracterizan el sistema estudiado.

b. Descripción de relaciones entre variables: Cada variable existe según una relación con otras variables, esto se explica y define el tipo de relación y clasificando la magnitud y tipo de influencia, lo cual se hace en una matriz.

c. Identificación de las variables clave con el Micmac: Busca identificar las variables clave, esenciales mediante una relación directa y luego una valoración indirecta. Se usan Matrices de Impacto Cruzadas (MIC) y otra MIC aplicada para una clasificación. Para detalles de éste y los otros programas computacionales de técnicas de prospectiva ver: http://www.3ie. fr/lipsor/lipsor_es/ (MICmac).

Una vez establecidas las variables externas e internas del sistema estudiado se definieron, de manera que se comprendiera de forma precisa su significado, las cuales se presenta en las siguientes tablas, clasificándolas cada una de ellas en: Variables Económicas, Variables físicas y ambientales, Variables sociopolíticas, Técnico operativo del sector eléctrico, Institucionales (organizaciones, normas y reglas del juego)

El análisis se inició con un grupo de variables entre 60 y 70 , de las cuales a partir de la elaboración de la matriz que se presento a profesionales del sector eléctrico, se fue estableciendo la importancia de cada variable a partir de diferentes criterios:

a. Se cuestionó aquellas variables que implícitamente podrían estar consideradas en otras variables o que resultaban poco claras de acuerdo a la definición que se había realizado. Para este proceso se contó con el criterio de profesionales o expertos conocedores del sector eléctrico, quienes tuvieron acceso a las matrices originales y las definiciones de las variables. A partir de esto se realizaron sesiones de trabajo con los profesionales, lo que permitió desechar algunas variables.

b. Las primeras versiones de la matriz presentada fueron elaboradas en Excel, lo cual permitió con base en las reglas de valor definidas, darles una calificación sobre el grado de influencia de cada variable sobre las demás. Este proceso lo realizó el investigador y posteriormente les fue entregado a otros investigadores la matriz para que estableciera las principales discrepancias, acuerdos o dudas. Con base en sesiones de trabajo se llegó a ajustar la matriz original con el criterio de los expertos.

c. Con base en la sumatoria de las influencias (filas) de cada una de las variables se analizó aquellas que tenían un bajo porcentaje de influencia, decidiéndose eliminar las variables poco influyentes.

d. Un elemento adicional fue que el análisis antes mencionado se realizó para dos situaciones, la actual y la potencial o futura. En algunos casos algunas variables resultaban poco relevantes en la actualidad, pero en el contexto de la reforma del sector eléctrico resultaban relevantes para el futuro.

Para establecer la importancia y el grado de dominio de las variables externas se elaboró una matriz denominada Matriz de Importancia y Dominio (MIDO; Fig.4) (Del Toro 2004).

En la matriz (Fig. 5), se distinguen:

- Zona A: Los cambios críticos, retos de futuro: constituyen los cambios importantes que no se dominan actualmente.

- Zona B: Cambios importantes bien controlados.

- Zona C: Cambios poco importantes que no se dominan, no es grave, se denomina puntos débiles no culpables.

- Zona D: Son los cambios poco importantes que se controlan, son los puntos fuertes, de los cuales usualmente se habla.

Seguidamente se presentan las variables externas en la matriz de importancia y dominio, para la situación actual, es decir el sector eléctrico sin reformas

En el Cuadro 2 se hace un esquema del proceso que se seguirá y los indicadores resultantes de cada matriz que permitirán realizar el análisis. En general el análisis que se presenta en este artículo se concentra en los resultados de la MIIPP.

La matriz de análisis estructural es la matriz de influencia directa actual (MID), que alimenta la base de datos del MICMAC, se emplea matrices, aplicando algebra matricial, 


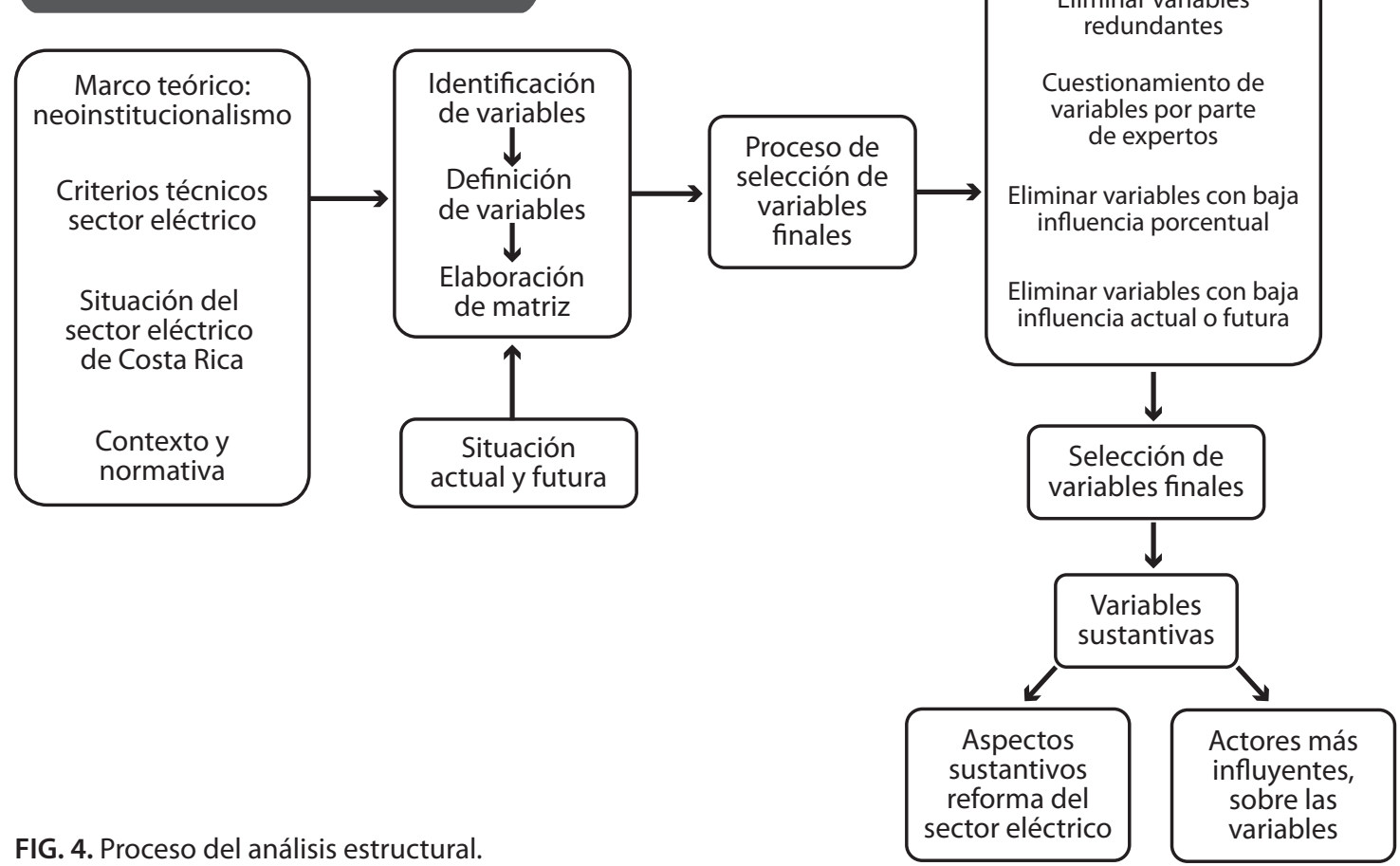

\begin{tabular}{|l|c|c|c|}
\hline \multirow{2}{*}{$\begin{array}{c}\text { Importancia } \\
\text { del cambio }\end{array}$} & Fuerte & $\mathrm{A}$ & $\mathrm{B}$ \\
\cline { 3 - 4 } & Débil & $\mathrm{C}$ & $\mathrm{D}$ \\
\hline \multirow{2}{*}{$\begin{array}{c}\text { MIDO: Matriz de } \\
\text { Importancia y Dominio }\end{array}$} & Débil & Fuerte \\
\cline { 3 - 4 } & \multicolumn{2}{|c|}{ Dominio actual } \\
\hline
\end{tabular}

FIG. 5. Matriz de importancia y dominio

en donde se llevan a cabo una serie de interacciones, hasta obtener la influencia y dependencia de cada variable, junto con otras salidas del programa que ayudan a establecer la importancia de las variables. Para detalles ver: http://www.3ie.fr/lipsor/lipsor_es/, al cual se le incluyen los efectos potenciales $(P)$ que se podrían dar en el futuro, de acuerdo a las consideraciones que esté considerando el analista, en nuestro caso una reforma del sector eléctrico y cambios en el entorno.

Las matrices de análisis indirecto actual y potencial surgen de los procesos de interacción del programa computacional; mediante cálculos de algebra matricial. En este trabajo se hace énfasis en los resultados de la Matriz de Influencia indirecta potencial, el cual integra los resultados que se darían en el futuro ante una reforma

Para las variables del sistema eléctrico de Costa Rica, cada una de ellas está relacionada a un indicador de motricidad y un indicador de dependencia sobre todo el sistema. Para efectos ilustrativos es posible mostrar en un plano la motricidad-dependencia (directa, indirecta o potencial) después de haber efectuado la corrida con el programa MICMAC. Seguidamente en la Fig. 6, se muestra la estructura del plano (Del Toro 2004, Mojica 2006).

Cada uno de los sectores del plano tiene un significado como seguidamente se indica:

Sector 1: Variables muy motrices y poco dependientes.

Sector 2: Variables a la vez muy motrices y muy dependientes.

Sector 3:Variables poco motrices y muy dependientes.

Sector 4: Variables poco motrices y poco dependientes (próximas al origen).

Sector 5: Variables medianamente motrices y/o dependientes. 
CUADRO 2

Esquema de las matrices y aspectos a analizar en el Análisis Estructural mediante MICMAC

\begin{tabular}{l|l|l}
\hline \multicolumn{2}{c}{ Nivel } & \multicolumn{1}{c}{ Indicadores } \\
\hline \multirow{2}{*}{$\begin{array}{l}\text { Matriz de influencia } \\
\text { directa (MID) }\end{array}$} & Matriz de influencia directa actual (MIDA) & $\begin{array}{l}\text { Suma de valores de filas y columnas } \\
\text { Porcentaje de fila y columna del total }\end{array}$ \\
\cline { 2 - 3 } & Matriz de influencia directa potencial (MIDP) & Plano de influencia y dependencia \\
\hline \multirow{2}{*}{$\begin{array}{l}\text { Matriz de influencia } \\
\text { indirecta (MII) }\end{array}$} & Matriz de influencia indirecta actual (MIIA) & Gráfico de influencias \\
\cline { 2 - 3 } & $\begin{array}{l}\text { Matriz de influencia indirecta potencial } \\
\text { (MIIP) }\end{array}$ & $\begin{array}{l}\text { Clasificación variables, influencia y } \\
\text { dependencia } \\
\text { Plano de desplazamientos } \\
\text { Proporciones }\end{array}$
\end{tabular}

\section{Análisis estructural del sector eléctrico}

En esta sección se aplica el análisis estructural para establecer las variables que son relevantes en la situación actual y futura con potenciales reformas neoclásicas del sector eléctrico de Costa Rica.

\section{Selección y definición de las variables externas e internas}

Con base en las variables que fueron finalmente seleccionadas se procedió a definirlas y clasificarlas, tal y como se detalla en los Cuadros 3, 4 y 5 para las variables externas y Cuadros 6, 7, 8 y 9 para las variables internas.

Las variables internas presentadas son aquellas que según el análisis efectuado permitieron rescatar los rasgos más relevantes del sistema eléctrico y que influyen y explican en mayor medida las decisiones, acciones y posibles resultados, incidiendo sobre los objetivos, comportamiento, recursos, conflictos y potenciales acuerdos por parte de los actores sociales.

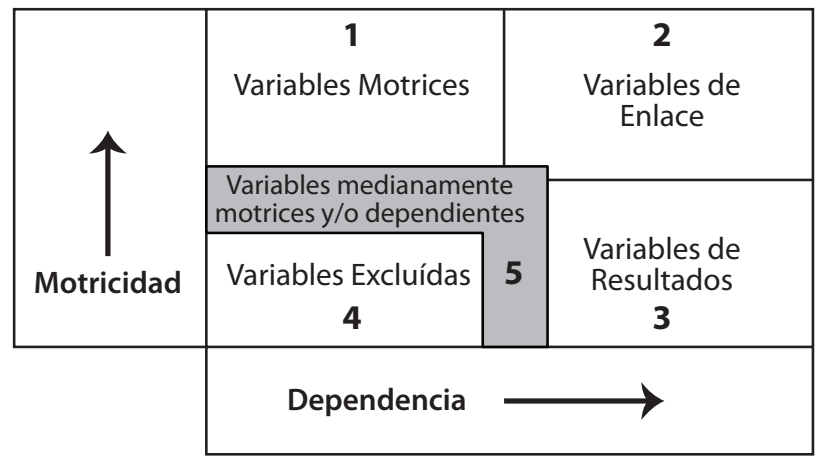

FIG. 6. Plano de motricidad y dependencia. Fuente: Del Toro 2004

\section{CUADRO 3}

Definición de variables económicas externas relacionadas con el sistema eléctrico de Costa Rica.

\begin{tabular}{lll}
\hline Vi & \multicolumn{1}{c}{$\begin{array}{c}\text { Variable económica } \\
\text { externa }\end{array}$} & \multicolumn{1}{c}{ Definición } \\
\hline Nivel de actividad & $\begin{array}{l}\text { Es la dinámica de las actividades productivas expresada en la producción de la } \\
\text { economía medida por medio del Producto Interno Bruto, su tasa de crecimiento y } \\
\text { las variables asociadas a este, como el consumo, la inversión, las exportaciones y el } \\
\text { empleo }\end{array}$ \\
& $\begin{array}{l}\text { Es el conjunto de disposiciones y directrices del Poder Ejecutivo para la articulación } \\
\text { Política de inversión y de } \\
\text { gasto público }\end{array}$ & $\begin{array}{l}\text { de una política de inversión y gasto público, pudiendo tener estas diferentes } \\
\text { orientaciones de política desde restrictivas a expansivas, de participaciones } \\
\text { públicas, privadas o ambas. }\end{array}$
\end{tabular}


CUADRO 3 (Continuación...)

Definición de variables económicas externas relacionadas con el sistema eléctrico de Costa Rica.

\begin{tabular}{ccc}
\hline Vi & $\begin{array}{c}\text { Variable económica } \\
\text { externa }\end{array}$ & Definición \\
\hline
\end{tabular}

3

Política de regulación de la economía.

$4 \quad$ Situación fiscal del país

Marco normativo de supervisión, permisos y

5 evaluación a las actividades económicas de las organizaciones públicas...

Políticas y acciones de los organismos financieros

6 internacionales con respecto a la participación pública en la economía

7

Criterios y dinámica de la inversión extranjera directa

8

Precio internacional de los derivados del petróleo.

Política de integración económica del país.
Son las orientaciones del Estado a través de sus poderes que definen ciertas características de intervención por parte de diferentes entidades a las actividades públicas y privadas con ciertos propósitos, generalmente justificados por el interés general. Pueden pasar de una alta intervención por medio de las organizaciones públicas a una baja regulación inspirados en el libre mercado.

Es la diferencia entre los ingresos (por impuestos y otros) y gastos corrientes (gasto en educación, salud, salarios, etc.) y el pago del servicio de la deuda del Poder Ejecutivo. Se puede obtener para el Gobierno Central, así como un déficit consolidado de todas las instituciones y organizaciones del sector público.

Son el conjunto de disposiciones establecidas por el Estado para normar, aprobar, supervisar y evaluar actividades económicas, en especial el desarrollo de obras de infraestructura pública, a través de organizaciones establecidas para ello como: Ministerio de Hacienda, Banco Central, Ministerio de Planificación, Contraloría General de la República.

Son los enfoques, orientaciones ideológicas, modelos económicos expresados en directrices y políticas que dirigen las investigaciones, propuestas, financiamiento y condicionalidades a los Estados para acceder a recursos financieros y poder tener una valoración positiva en el ámbito económico internacional de su gestión.

Es el comportamiento definido por las pautas, razones y condiciones que determinan que los agentes económicos lleven a cabo inversiones en empresas, actividades u obras de infraestructura en diferentes áreas por parte de extranjeros por medio de flujos de recursos financieros externos.

Es el valor monetario al cual se cotizan en los mercados internacionales los diferentes derivados del petróleo a diferentes horizontes temporales.

Son las disposiciones, lineamientos y acciones por medio de iniciativas como convenios internacionales, acuerdos de asociación o cooperación que buscan facilitar actividades económicas de diversa índole, mediante la disminución y eliminación de restricciones, homologación de disposiciones, entre otros, con el fin de facilitar el comercio, el intercambio y la inversión en diferentes ámbitos.

\section{CUADRO 4}

Definición de variables físicas y ambientales externas, relacionadas con el sistema eléctrico de Costa Rica.

\begin{tabular}{cll}
\hline Vi & $\begin{array}{l}\text { Variable física y ambiental } \\
\text { externa }\end{array}$ & \multicolumn{1}{c}{ Definición } \\
\hline 10 & $\begin{array}{l}\text { Dotación y posibilidad de } \\
\text { explotación de recursos } \\
\text { energéticos. }\end{array}$ & $\begin{array}{l}\text { Es el inventario de recursos energéticos existentes, así como la viabilidad de su } \\
\text { empleo por parte del país para actividades económicas, dada la normativa, los usos } \\
\text { y las prioridades nacionales existentes. }\end{array}$ \\
& $\begin{array}{l}\text { Incidencia del cambio } \\
\text { climático. }\end{array}$ & $\begin{array}{l}\text { Es el conjunto de efectos que puede generar en diferentes horizontes temporales } \\
\text { ambiente. }\end{array}$ \\
$12 \begin{array}{l}\text { Patrones de uso de los cambio climático sobre las diferentes actividades humanas y el } \\
\text { recursos naturales y el } \\
\text { ambiente. }\end{array}$ & $\begin{array}{l}\text { Es la forma como se emplean o no los recursos naturales y el ambiente con base en } \\
\text { normas éticas, culturales, técnicas, legales, económicas y las condiciones naturales } \\
\text { preestablecidas. }\end{array}$
\end{tabular}




\section{CUADRO 5}

Definición de variables sociopolíticas externas, relacionadas con el sistema eléctrico de Costa Rica.

\begin{tabular}{|c|c|}
\hline Vi & $\begin{array}{c}\text { Variable sociopolítica } \\
\text { externa }\end{array}$ \\
\hline 13 & $\begin{array}{l}\text { Mecanismos de } \\
\text { participación social y } \\
\text { rendición de cuentas a los } \\
\text { ciudadanos }\end{array}$ \\
\hline 14 & $\begin{array}{l}\text { Capacidad de movilización } \\
\text { social y otros medios } \\
\text { legítimos para incidir en las } \\
\text { políticas públicas }\end{array}$ \\
\hline 15 & $\begin{array}{l}\text { Posibilidad para formar } \\
\text { alianzas para una reforma } \\
\text { neoclásica }\end{array}$ \\
\hline 16 & $\begin{array}{l}\text { Costumbres y reglas de } \\
\text { comportamiento de los } \\
\text { actores sociales. }\end{array}$ \\
\hline 17 & $\begin{array}{l}\text { Capacidad de gestión de las } \\
\text { organizaciones. }\end{array}$ \\
\hline 18 & $\begin{array}{l}\text { Respeto y aplicación de } \\
\text { las normativas y políticas } \\
\text { públicas. }\end{array}$ \\
\hline
\end{tabular}

\section{Definición}

Son el conjunto de disposiciones legales, reglamentarias o culturales que el Estado y la sociedad ha construido para que los ciudadanos puedan tener la posibilidad de participar en la discusión, concientización, evaluación o toma de decisiones que son de relevancia para un segmento o toda la colectividad social y que inciden en la dinámica de convivencia social.

Es la facultad y poder de determinados actores sociales para aglutinar, organizar y acordar una posición que se transforman en acciones sociales concretas, mediante diferentes recursos, para el logro de un objetivo que afectan las reglas de convivencia social.

Es la capacidad de los sectores políticos en determinados horizontes temporales de impulsar reformas que promueven el uso del mercado y la privatización, por medio de agendas, propuestas comunes y votos mediante una cohesión y gestión en la búsqueda del logro de sus objetivos.

Es el conjunto de normas formales o informales, usos y costumbres establecidas entre los diferentes actores sociales del país, que restringen o definen pautas de comportamiento en determinadas circunstancias y situaciones.

Son las dotaciones en recursos de diferente tipo, facultades y organización que permiten a un ente poder llevar a cabo actividades con un grado determinado de eficiencia, eficacia y efectividad para el logro de los objetivos definidos para éste.

Son las actitudes y el ambiente cultural, organizacional de los actores sociales para el cumplimiento de las normas y políticas establecidas, así como la capacidad de estos de aplicarla y velar por su cumplimiento.

CUADRO 6

Definición de variables económicas internas, relacionadas con el sistema eléctrico de Costa Rica.

\begin{tabular}{cc}
\hline Vi & $\begin{array}{c}\text { Variable económica } \\
\text { interna }\end{array}$ \\
\hline 19 & Precio de la electricidad \\
20 & Oferta de electricidad \\
21 & Demanda de electricidad \\
22 & $\begin{array}{l}\text { Competencia en la } \\
\text { producción de electricidad }\end{array}$
\end{tabular}

23 Tarifas servicios eléctricos

Es el valor monetario asignado a la electricidad mediante una medida específica (K., MWh) para diferentes fases del ciclo de los servicios eléctricos (al producirla, a clientes mayoristas, a clientes finales convencionales), definido por diversos medios como la: regulación, el mercado o el acuerdo entre las partes.

Es la cantidad de electricidad que un actor del sector eléctrico o el conjunto de estos están dispuestos a vender en un horizonte temporal y una zona geográfica, a diferentes precios.

Es la cantidad de electricidad que un actor del SE o el conjunto de estos están dispuestos a comprar en un horizonte temporal y una zona geográfica, a diferentes precios.

Es el comportamiento de generadores eléctricos con ciertos objetivos que participan en un espacio y tiempo determinado por la participación de mercado, cantidad de participantes, tipo de plantas y las reglas establecidas a estos.

Son los valores monetarios definidos a una medida de electricidad determinada usualmente en Kwh., a los diferentes proveedores de servicios eléctricos en la cadena de valor, cuando éstos son regulados bajo el principio de costo. 
CUADRO 6 (Continuación...)

Definición de variables económicas internas, relacionadas con el sistema eléctrico de Costa Rica.

\begin{tabular}{|c|c|c|}
\hline $\mathbf{V i}$ & $\begin{array}{l}\text { Variable económica } \\
\text { interna }\end{array}$ & Definición \\
\hline 24 & Mercado mayorista nacional & $\begin{array}{l}\text { Es la instancia de participación de agentes calificados, que llevan a cabo } \\
\text { intercambios de compra venta de electricidad, en ciertas cantidades, lugares y } \\
\text { plazos, de acuerdo a los intereses de éstos y según la normativa que se crearían } \\
\text { con la reforma del sector eléctrico }\end{array}$ \\
\hline 25 & $\begin{array}{l}\text { Número y cuota de } \\
\text { mercado de productores }\end{array}$ & $\begin{array}{l}\text { Es la cantidad de productores, su peso relativo en la generación total del sistema } \\
\text { nacional, así como las características de las plantas, que les permiten poder } \\
\text { acceder a un porcentaje de las necesidades del SE. }\end{array}$ \\
\hline 26 & $\begin{array}{l}\text { Número y cuota } \\
\text { de mercado de los } \\
\text { demandantes }\end{array}$ & $\begin{array}{l}\text { Es la cantidad de consumidores, su peso relativo en la demanda total del sistema } \\
\text { nacional, así como las características de sus necesidades de electricidad en el } \\
\text { tiempo y el espacio, que les da ciertas necesidades en el SE. }\end{array}$ \\
\hline 27 & $\begin{array}{l}\text { Participación de actores en } \\
\text { el mercado regional }\end{array}$ & $\begin{array}{l}\text { Es la posibilidad de que los actores del SE del país puedan participar como agentes } \\
\text { del mercado regional de Centro América, según las disposiciones nacionales y del } \\
\text { tratado marco del mercado. }\end{array}$ \\
\hline
\end{tabular}

CUADRO 7

Definición de variables técnicas-operativas internas, relacionadas con el sistema eléctrico de Costa Rica.

\begin{tabular}{|c|c|c|}
\hline Vi & $\begin{array}{l}\text { Variable técnica- } \\
\text { operativa interna }\end{array}$ & Definición \\
\hline 28 & $\begin{array}{l}\text { Seguridad de suministro } \\
\text { eléctrico }\end{array}$ & $\begin{array}{l}\text { Es el objetivo básico de un sistema eléctrico, el cual se define como el hecho } \\
\text { de asegurar el abastecimiento de electricidad en cantidad y calidad a todos los } \\
\text { usuarios del servicio público, en el tiempo y en todas las zonas geográficas en } \\
\text { donde se atienda, con ciertas normas y probabilidad de seguridad. }\end{array}$ \\
\hline 29 & $\begin{array}{l}\text { Criterios para determinar } \\
\text { inversiones en generación, } \\
\text { transmisión y distribución }\end{array}$ & $\begin{array}{l}\text { Son las orientaciones que las organizaciones del sector asumen o bien las reglas } \\
\text { del juego que les han definido, para asignar recursos a la expansión de las obras } \\
\text { de infraestructura necesarias para asegurar el abastecimiento eléctrico, en las } \\
\text { condiciones de cantidad y calidad definidas para el sector. }\end{array}$ \\
\hline 30 & $\begin{array}{l}\text { Características y } \\
\text { combinación de las fuentes } \\
\text { de generación del sector } \\
\text { eléctrico (Mix) }\end{array}$ & $\begin{array}{l}\text { Son las fuentes de generación eléctrica existentes en un SE, el cual operado de } \\
\text { forma integrada, define ciertas pautas de operación de las plantas, de acuerdo } \\
\text { a: los costos, disposición de las fuentes, el lugar, la disposición de líneas de } \\
\text { transmisión, el lugar y forma del consumo y características de la energía producida, } \\
\text { las cuales son específicas a cada sector eléctrico. }\end{array}$ \\
\hline 31 & $\begin{array}{l}\text { Capacidad y características } \\
\text { de la red de transmisión de } \\
\text { electricidad }\end{array}$ & $\begin{array}{l}\text { Es el diseño de la red (lineal, en malla u otra), su capacidad de transporte de } \\
\text { electricidad, su distribución geográfica, seguridad y especificidades técnicas que } \\
\text { permiten cierto trasiego de electricidad y llena ciertas necesidades al sistema } \\
\text { eléctrico. }\end{array}$ \\
\hline 32 & $\begin{array}{l}\text { Conservación y uso } \\
\text { eficiente de la electricidad }\end{array}$ & $\begin{array}{l}\text { Es el conjunto de acciones de gestión, mejora tecnológica y cambios culturales e } \\
\text { institucionales que permiten usar la energía eléctrica de mejor forma de acuerdo a } \\
\text { ciertos parámetros técnicos establecidos. }\end{array}$ \\
\hline
\end{tabular}




\section{CUADRO 8}

Definición de variables institucionales, (organizaciones, normas y reglas del juego) internas, relacionadas con el sistema eléctrico de Costa Rica.

\begin{tabular}{|c|c|c|}
\hline Vi & Variable externa & Definición \\
\hline 33 & $\begin{array}{l}\text { Normativa, requisitos y } \\
\text { obligaciones ambientales } \\
\text { al SE }\end{array}$ & $\begin{array}{l}\text { Es el conjunto de disposiciones, trámites, estudios, requisitos y procesos a los } \\
\text { cuales deben someterse las organizaciones del SE para desarrollar y operar. }\end{array}$ \\
\hline 34 & Tipo de Planificación en SE. & $\begin{array}{l}\text { Es el tipo de disposición que mediante normativa específica, acuerdo o costumbre } \\
\text { define la forma como se ordena en el tiempo las necesidades de inversiones } \\
\text { y acciones por parte del SE para proveer el suministro eléctrico en cantidad y } \\
\text { calidad. }\end{array}$ \\
\hline 35 & $\begin{array}{l}\text { Competencias de las } \\
\text { organizaciones. }\end{array}$ & $\begin{array}{l}\text { Es el conjunto de disposiciones que definen las responsabilidades y obligaciones } \\
\text { de las organizaciones del sector estableciéndoles el alcance de sus actividades, } \\
\text { según la normativa existente, los usos y las costumbres }\end{array}$ \\
\hline 36 & $\begin{array}{l}\text { Eficiencia de las } \\
\text { organizaciones del sector }\end{array}$ & $\begin{array}{l}\text { Es la capacidad de las organizaciones de brindar diferentes servicios eléctricos a } \\
\text { los clientes en un tiempo y con unos recursos determinados. }\end{array}$ \\
\hline 37 & $\begin{array}{l}\text { Grado de disociación de las } \\
\text { organizaciones. }\end{array}$ & $\begin{array}{l}\text { Es la forma como los entes participantes separan actividades, las cuales en el } \\
\text { marco de un mercado, pueden ser incompatibles, pudiendo requerir desde } \\
\text { separación de costos, separación legal de empresas de generación y distribución, } \\
\text { hasta la venta o privatización de las organizaciones. }\end{array}$ \\
\hline 38 & Tipo de regulación en el SE. & $\begin{array}{l}\text { Es el conjunto de disposiciones legales, costumbres, cultura y capacidades de las } \\
\text { organizaciones que han definido cierta forma y alcance de establecer las reglas } \\
\text { del juego, a la provisión de los diferentes servicios eléctricos de la cadena de } \\
\text { valor, proveído por diferentes organizaciones que están sometidas a la normativa } \\
\text { regulatoria existente. }\end{array}$ \\
\hline 39 & $\begin{array}{l}\text { Incentivos para fuentes } \\
\text { renovables. }\end{array}$ & $\begin{array}{l}\text { Es el conjunto de medidas tomadas en el SE para promover la generación con } \\
\text { fuentes renovables de electricidad. }\end{array}$ \\
\hline & Definición de variables socic & $\begin{array}{c}\text { CUADRO } 9 \\
\text { Dolíticas y físicas internas, relacionadas con el sistema eléctrico de Costa Rica. }\end{array}$ \\
\hline Vi & $\begin{array}{l}\text { Variable sociopolítica } \\
\text { externa }\end{array}$ & Definición \\
\hline 40 & $\begin{array}{l}\text { Influencia política en toma } \\
\text { de decisiones técnicas. }\end{array}$ & $\begin{array}{l}\text { Es el hecho de que los actores políticos influyan en la definición, selección de } \\
\text { decisiones relevantes en el sector eléctrico, sin que medien argumentaciones } \\
\text { técnicas y racionales. }\end{array}$ \\
\hline 41 & $\begin{array}{l}\text { Principios de solidaridad y } \\
\text { universalidad }\end{array}$ & $\begin{array}{l}\text { Es la orientación que permite al marco regulatorio financiar mediante tarifas u } \\
\text { otros medios el consumo o la expansión de la red a ciudadanos u organizaciones } \\
\text { de bajo ingreso o bien si la ampliación no es viable financieramente. }\end{array}$ \\
\hline 42 & $\begin{array}{l}\text { Percepción e importancia } \\
\text { de organizaciones en la } \\
\text { sociedad }\end{array}$ & $\begin{array}{l}\text { Es la imagen, aprecio, valoración que tienen las organizaciones del sector eléctrico } \\
\text { para determinados segmentos de la sociedad o la generalizada que se obtiene del } \\
\text { colectivo social. }\end{array}$ \\
\hline 43 & $\begin{array}{l}\text { Objetivos de los actores } \\
\text { sociales }\end{array}$ & $\begin{array}{l}\text { Son los motivadores de las acciones, posiciones y estrategias, pudiendo ser de } \\
\text { diferente tipo, según la función que tenga con respecto al sector eléctrico. }\end{array}$ \\
\hline \multicolumn{3}{|c|}{ Variable física externa } \\
\hline 44 & $\begin{array}{l}\text { Potencial de generación } \\
\text { eléctrica de Costa Rica }\end{array}$ & $\begin{array}{l}\text { Está definida por el conjunto de opciones de generación eléctrica de diferentes } \\
\text { fuentes energéticas identificadas en el país, que poseen ciertas características } \\
\text { que lo hacen convertirse en posibles proyectos, conforme se lleven a cabo } \\
\text { investigaciones que permitan establecer su viabilidad efectiva. }\end{array}$ \\
\hline
\end{tabular}




\section{RESULTADOS}

En el Cuadro 10 se presenta la situación actual y futura de las variables en cuanto al dominio, desarrollo e importancia teniendo presente en el futuro un escenario de reforma neoclásica del sector eléctrico.

A continuación se presenta en la figura 7, la matriz MIDO resultante para las variables externas. En la parte interna de la matriz se indica el número de la variable según la valoración del dominio actual y la importancia.

Visualmente se pueden apreciar las diferencias que se dan entre la situación actual y futura. La figura siguiente muestra el cambio que se daría en el futuro con las variables externas bajo el contexto de una reforma del sector eléctrico neoclásica.

Teniendo en cuenta la posible evolución futura de las variables externas (Fig. 8), su importancia y grado de dominio por parte del sector eléctrico, se mantiene una situación similar a la presente, ubicándose en el plano A y C la mayoría de variables; se tiene un dominio débil. Únicamente las variables Incidencia del cambio climático (11) y Patrones de uso de los recursos naturales (12) tendrán una importancia mayor y sobre estos aspectos el sector eléctrico estaría mejorando su capacidad de dominio sobre ellas, a través de diferentes acciones de adaptación y dominio. Esto se aprecia al comparar las figuras 4 y 6 .

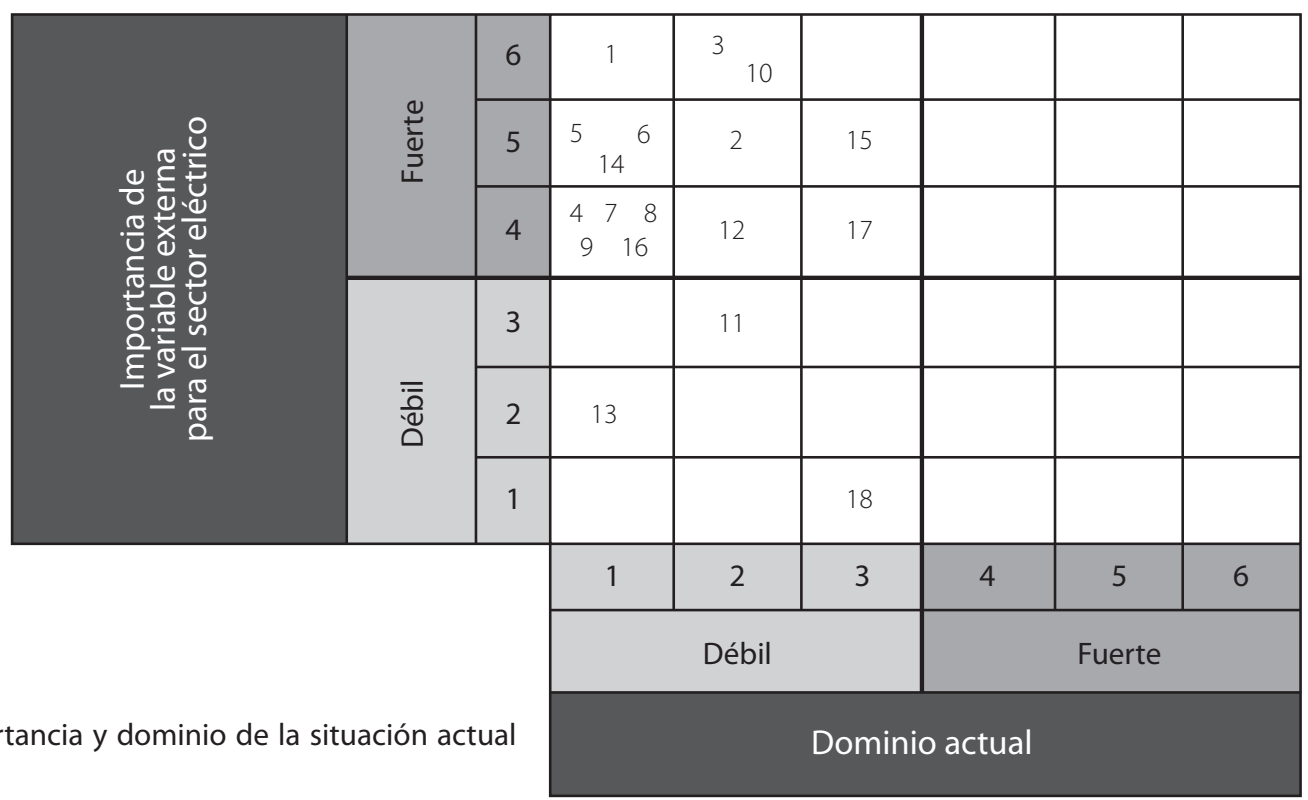

FIG. 7. Matriz de importancia y dominio de la situación actual para variables externas

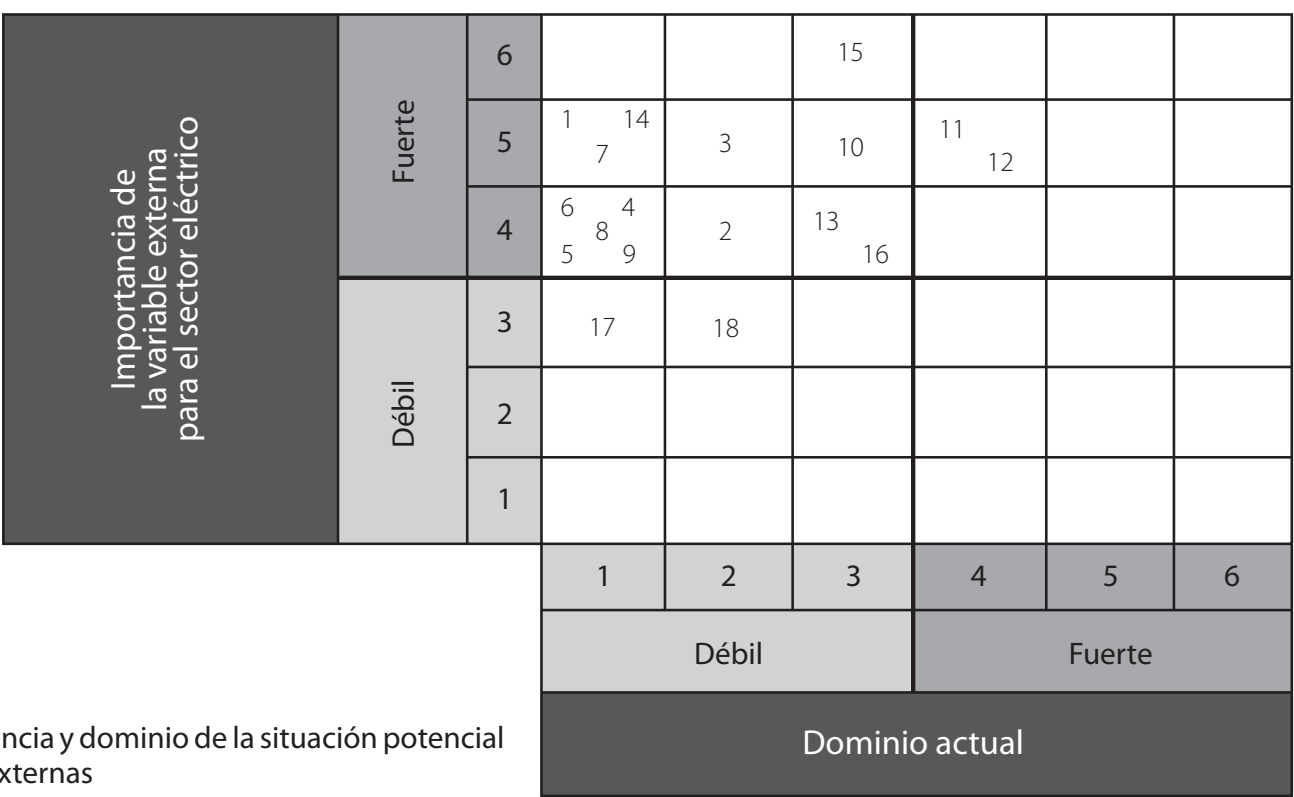

FIG. 8. Matriz de importancia y don
o futura para variables externas 


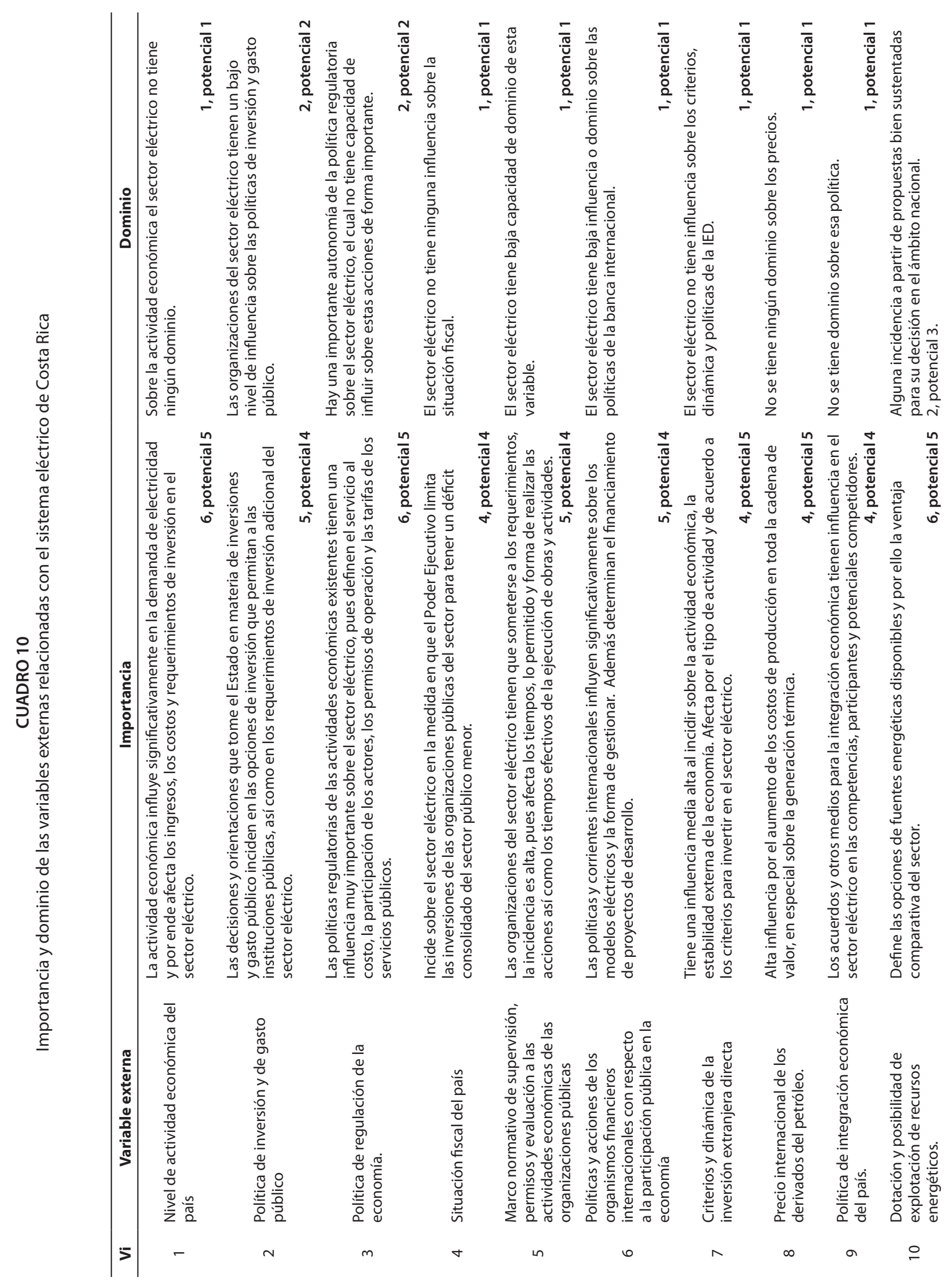




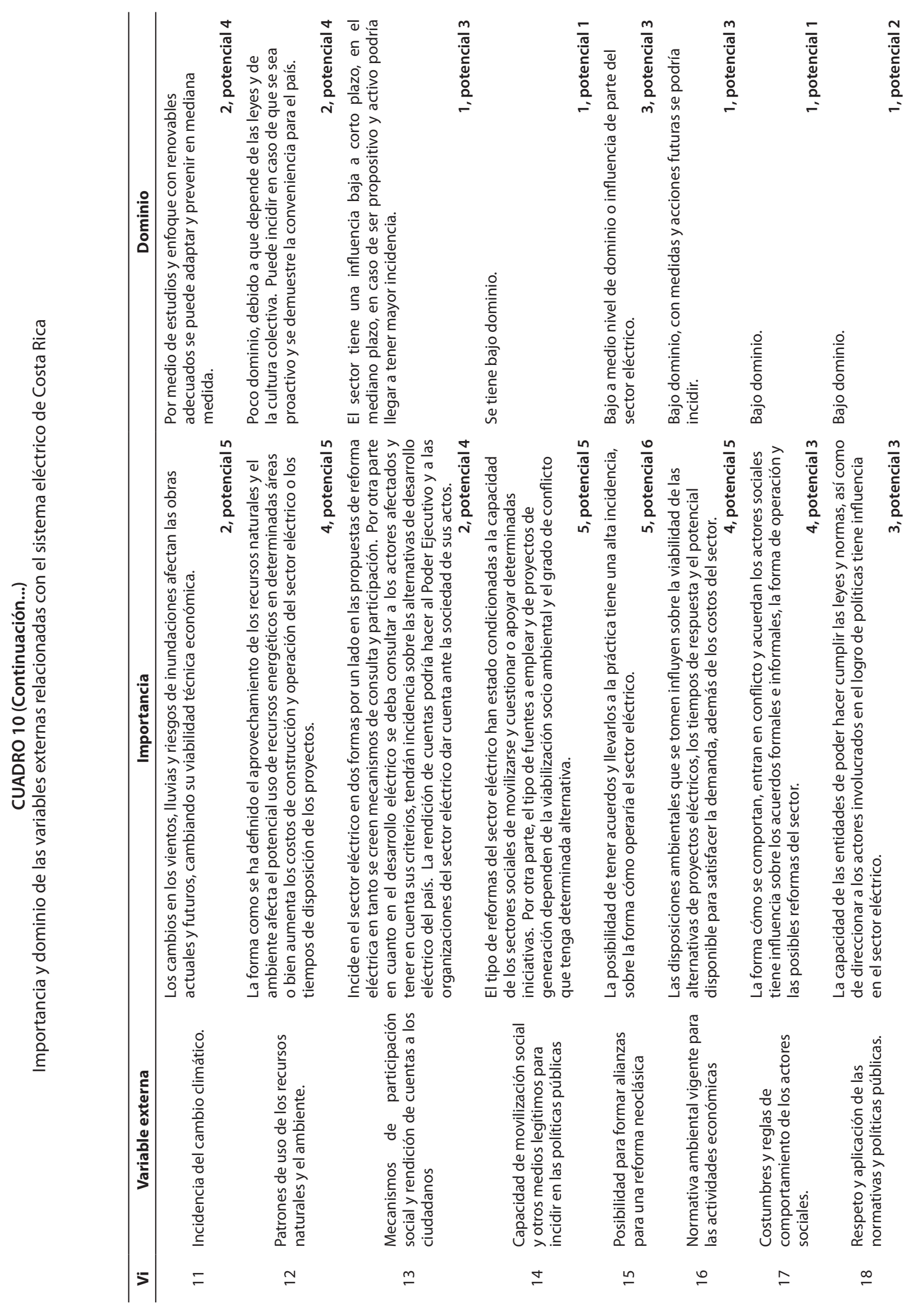


En la figura 9 se muestra la matriz con las variables internas en la situación presente y en la figura 10 se presenta la situación que se daría con éstas en una situación futura con los cambios del entorno más posible.

La Oferta de electricidad ( $\mathrm{Vi}=20$ ) seguirá teniendo limitaciones, aunque menores y por diferentes causas a las actuales; las restricciones institucionales existentes, los criterios para efectuar los cálculos de los agentes económicos y complejos e importantes aspectos ambientales seguirán o aumentarán su relevancia.
La Solidaridad social ( $\mathrm{Vi}=41)$ es una variable que hasta la actualidad ha sido bien manejada, pero que las nuevas reglas del juego podrían llevar a desajustes dependiendo del diseño de la reforma y por ende de las reglas del juego que se definan; en todo caso, la mayor complejidad y la competencia entre organizaciones del sector no parecieran propiciar las condiciones para considerar este importante aspecto, lo cual deberá corregirse.

La regulación del sector eléctrico $(\mathrm{Vi}=38)$ será uno de los ejes centrales de la discusión futura, dados los nuevos

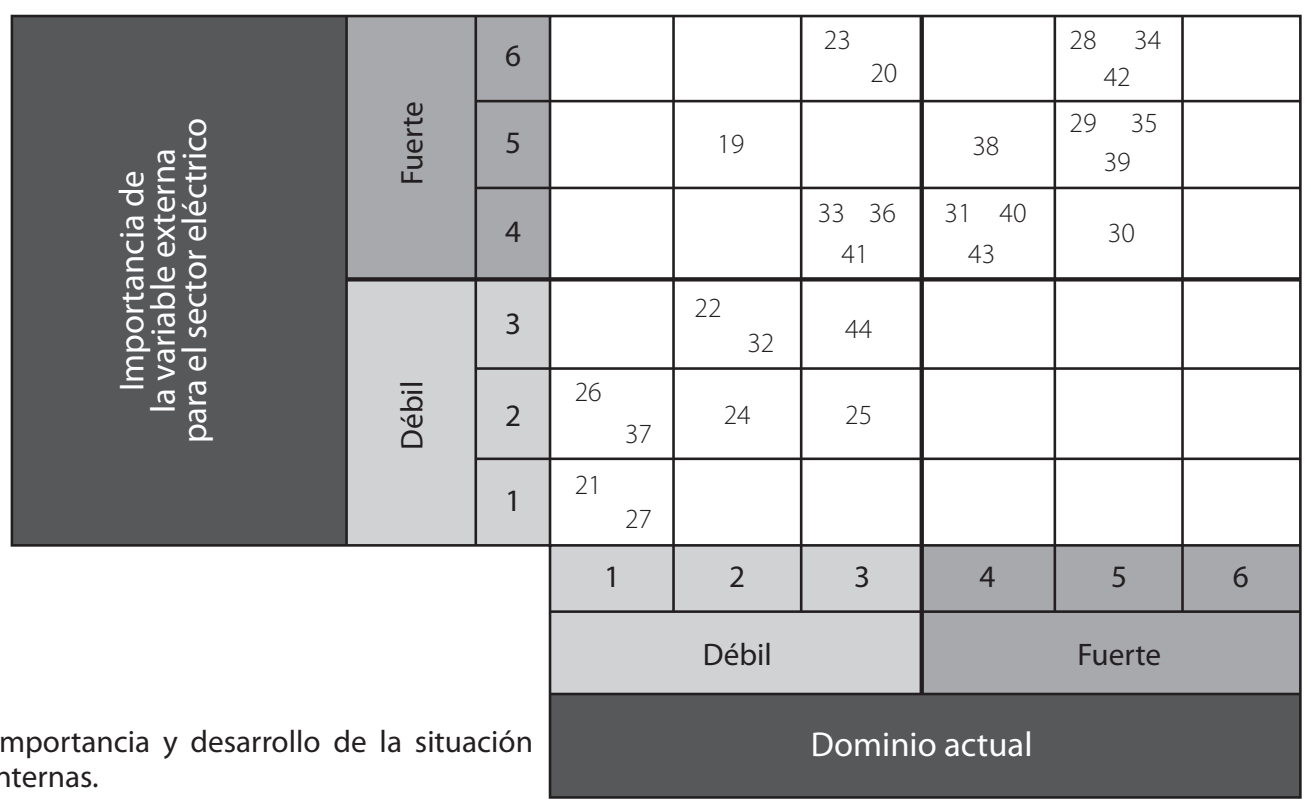

FIG. 9. Matriz de la importa
actual para variables internas.

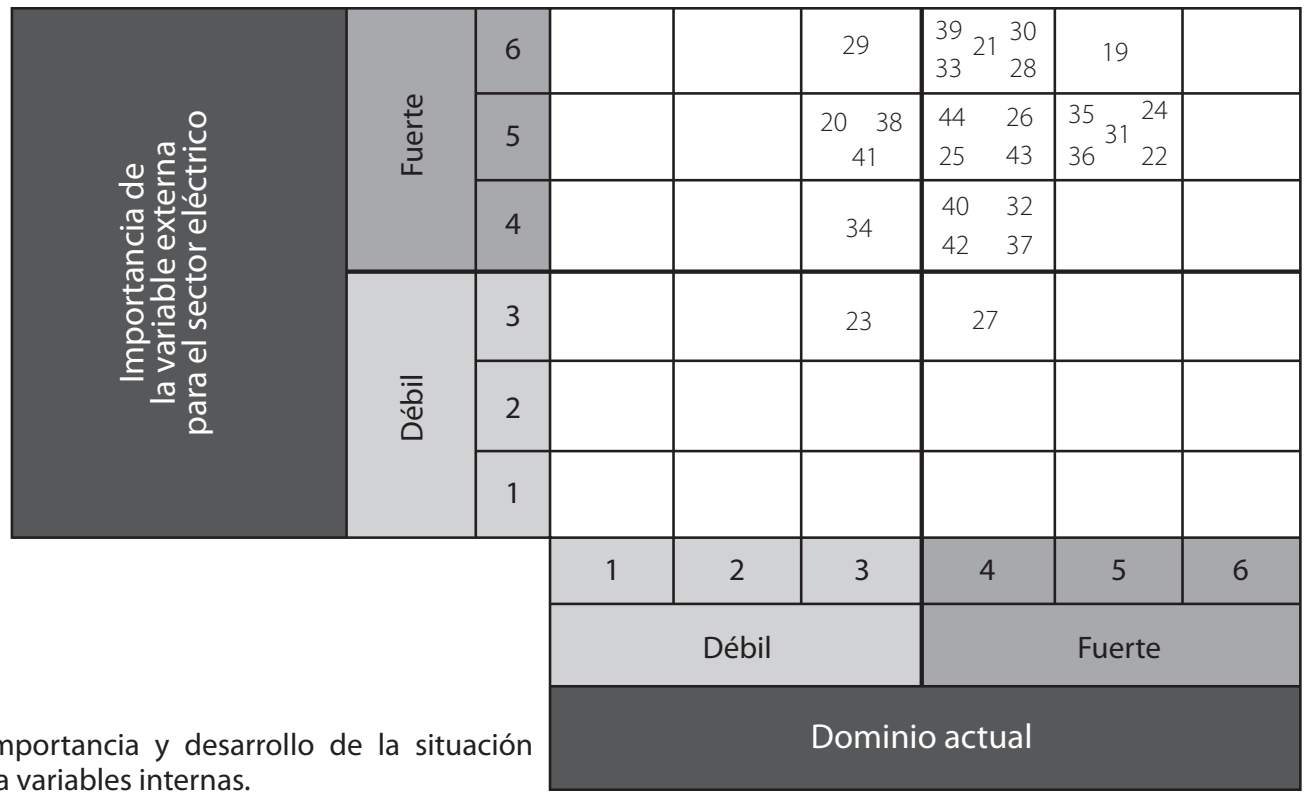

FIG. 10. Matriz de importancia y desarrol
potencial o futura para variables internas. 
ámbitos de regulación, la complejidad que podría tener un modelo eléctrico con reformas como pareciera marcar las tendencias actuales. En general, es difícil contar con una regulación acorde a los retos que planteará el futuro; su mejoramiento se podría dar conforme los problemas y el aprendizaje vayan dándose.

Destaca además que la planificación $(\mathrm{V} i=34)$ deja de tener la relevancia que ha tenido hasta ahora, lo cual eventualmente pasará de tener una alta influencia a una menor, quedando muchas de las posibles decisiones en manos del mercado, en caso de que prevalezcan las tendencias neoclásicas para el diseño y aprobación de la reforma. Se espera que la Demanda de electricidad $(\mathrm{Vi}=21)$, pueda ser influenciada de mejor forma en el futuro, dadas las restricciones y mayores costos de abastecimiento eléctrico futuro en el ámbito nacional e internacional.

Se prevé que continúe el problema con las tarifas $\mathrm{Vi}=23$, debiéndose ir depurando las reglas del juego, la capacidad de las organizaciones y la independencia política. Esto último plantea un potencial riesgo, pues al entrar en juego actores privados y buscar los actores el lucro, podría eventualmente usar de forma más intensa la influencia política para incidir en el diseño y aplicación de las reglas del juego para su beneficio.

Una variable fundamental que determina la expansión del sistema eléctrico para abastecer la demanda es la $\mathrm{Vi}=29$ "Criterios para determinar inversiones en generación, transmisión, distribución" Esta según el análisis realizado tiene la mayor importancia y tendría bajo nivel de desarrollo. Se daría alteración de aspectos que definen el comportamiento de la variable por las siguientes razones: no queda claro el papel de la planificación, si se tendría el comprador principal o único y el alcance del mercado interno o regional, todo lo cual lleva a mayor incertidumbre, riesgo y especulación por parte de los agentes, al no tener claros los criterios para tomar las decisiones de inversión.

Relacionada con las variables $\mathrm{Vi}=29$ y 23 , se encuentra la variable $\mathrm{Vi}=20$, "Oferta de Electricidad" esta tiene a futuro una alta importancia y un desarrollo débil. Esta situación se debe a la falta de claridad y criterio técnico en la definición de tarifas, la complejidad de los criterios para realizar las inversiones y que en el caso del desarrollo del mercado las reglas del juego no están suficientemente claras y esto haría que se den rezagos en la inversión. Unido a ello, el marco jurídico ambiental establece restricciones para el desarrollo de proyectos en ciertas zonas y define requisitos y normas relevantes para el desarrollo de proyectos. Las fuentes de financiamiento y los tiempos necesarios para tener la factibilidad técnica - económica y construir proyectos con fuentes renovables hacen que la oferta tenga restricciones para poder tener un desarrollo alto.
El tipo de regulación del sistema eléctrico $(\mathrm{Vi}=38)$, tiene que ver con el diseño que se logre del proceso de reforma; en cualquiera de los escenarios que podría tenerse de las reformas es complejo y determinante para las decisiones de los agentes del sector. En caso de que se desarrolle un mercado, el diseño y capacidad de implementación de una regulación no resultan fáciles de lograr, requiriendo un tiempo de pruebas y errores, así como el generar las capacidades de las organizaciones para ello.

De persistir la tendencia actual es posible que los subsidios a los sectores de más bajos recursos y la ampliación de la cobertura eléctrica a las zonas menos rentables $(\mathrm{V}=41)$ se vea disminuida. Los intereses de los sectores empresariales en el sentido de no querer pagar en sus tarifas subsidios cruzados al sector residencial es la razón básica para ello. La fuente de financiamiento de estos subsidios es de especial importancia, ya que la experiencia internacional ha mostrado que con recursos del fisco esto se vuelve muy poco sostenible a largo plazo.

\section{Elaboración de la matriz de impactos cruzados}

Como primera fase del análisis estructural se procederá a elaborar una matriz en donde se presentan en filas y columnas en el mismo orden las variables internas y externas, estableciendo las relaciones entre cada una de las variables con la siguiente calificación: (1) Influencia débil, (2) Influencia media, (3) Influencia fuerte, (P) Influencia potencial.

Previo a establecer si hay relación entre variables se deben responder tres preguntas (Del Toro 2004):

- ¿Ejerce la variable A una acción efectiva sobre la variable $B$, o la relación será más bien de $B$ hacia $A$ ?

- ¿Ejerce A una acción sobre B, o existe más bien una colinealidad, es decir, que una tercera variable $C$ actúa sobre A y B?

- ¿La relación entre A y B es directa, o más bien se realiza a través de otra variable $J$ de las incluidas en la lista?

En el futuro es posible que algunas variables que tienen una influencia baja en el presente, pasen a tener una influencia importante. Por ello, es conveniente tener en cuenta las relaciones potenciales $(P)$, que pueden agregarse a las relaciones para establecer el efecto de este hecho.

Con base en las variables definidas, las influencias establecidas entre ellas, las valoraciones realizadas y de acuerdo a las reglas de valor para brindarles la calificación se estima la matriz. La matriz está compuesta por 44 variables, de las cuales 18 son externas y 26 internas (del sector eléctrico). La matriz presenta en las filas la influencia que cada 
variable tiene sobre las otras (columnas), según la escala de valores definida. Se efectúo consultas a profesionales con importante experiencia en el sector eléctrico, ajustando los valores de la matriz con base en sus observaciones y el criterio del investigador.

Esta primera matriz se trabajó en una hoja de Excel, la cual luego fue exportada al programa MICMAC. La Matriz de Influencias Directas (MID) describe las relaciones directas entre las variables que definen el sistema (Apéndice 1). La matriz MID se completa teniendo en cuenta la escala siguiente: (0) Influencia nula, (1) Influencia leve, (2) Influencia media, (3) Influencia fuerte, (4) Influencia potencial.

La información fue obtenida a partir del criterio de expertos del sector eléctrico (participaron 4 expertos), con base en sesiones de trabajo con el investigador. Luego se incluyo la información base al programa MICMAC y se hicieron las corridas del modelo de matrices.
Según el plano de la figura 11, las variables que se consideran de enlace son "Tarifas del sector eléctrico" (TSE), "Seguridad de suministro de electricidad" (SSE), "Criterios para las inversiones en generación, transmisión y distribución" (CIGTD), "Objetivos de los Actores sociales" (OAS), "Precio de la Electricidad" (PE), (Vi =23,28, 29, 43,19, respectivamente) es decir variables de alta motricidad o influencia y alta dependencia. Estas variables son variables internas, que en general están asociadas con aspectos económicos, específicamente con la forma cómo se brindan las remuneraciones a los servicios y por ende los retornos sobre la inversión. La "Seguridad del suministro eléctrico" $(\mathrm{Vi}=28)$, es una variable influyente y dependiente de las variables del sistema, pues es el objetivo básico del sector eléctrico. Lo mostrado en la figura 11 se basa en lo que es la situación actual, es decir con base en los resultados que brindo la MIIA.

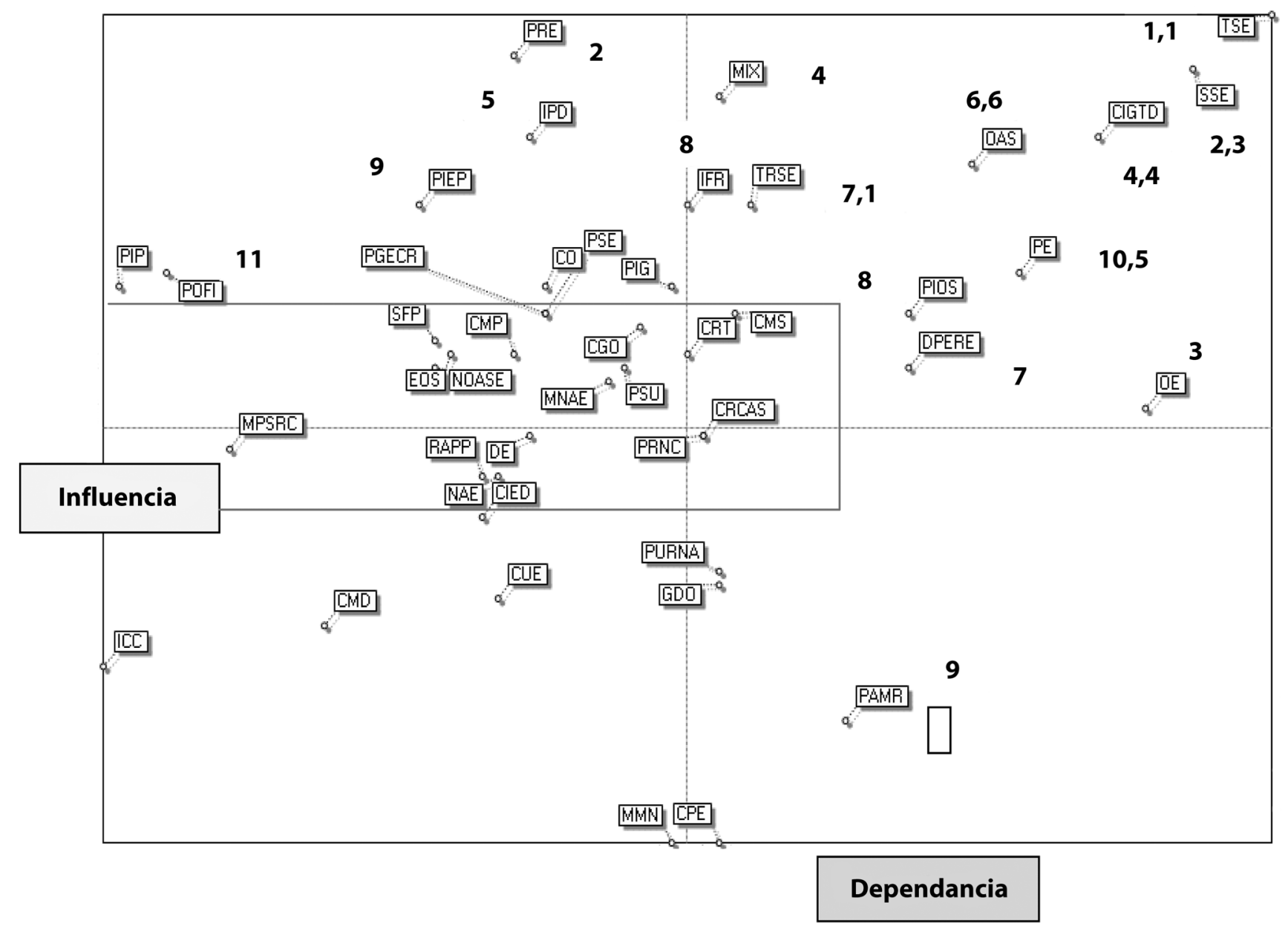

FIG. 6. Plano de influencias / dependencias directas. Fuente: Jiménez 2009. 
Con base en los resultados obtenidos de la MIIA obtenida con el MICMAC se establecen las variables esenciales del sistema bajo estudio, teniendo siempre en cuenta las variables que están en el cuadrante de las variables motrices, así como de manera secundaria las que son de enlace y de resultado:

a. Mercado mayorista nacional (MMN): El sector eléctrico en caso de una reforma de mercado dejará de tener la influencia de la regulación de las tarifas y la seguridad de suministro como variables que inciden sobre el sector eléctrico para pasar a ser el mercado mayorista que se crearía en el país. La incidencia de este mercado pese a que no se espera que se transen toda la electricidad, influirá en toda la forma de operar y desarrollar el sistema eléctrico del país, requiriendo ajustes en los aspectos que consideran las variables internas del sistema diseñado para efectos analíticos y que integra los aspectos sustantivos de éste. El MMN modificará las reglas del juego para la generación e inversión de los agentes que participarán en este, lo cual tendrá una fuerte incidencia en todo el sector eléctrico.

b. Grado de disociación de las organizaciones del sector eléctrico (GDO): En general en caso de que se dé una separación por costos, jurídica o bien venta (privatización), su efecto y capacidad de influencia sobre todo el sector eléctrico es de grandes dimensiones, la forma cómo operan las empresas, la potencial competencia, la estructura de costos, los objetivos de las organizaciones, la forma de regulación e inversión, entre otros elementos serán influenciados por este aspecto.

c. Competencia en la producción de electricidad (CPE): La creación de condiciones para competencia entre los generadores de electricidad, tiene una fuerte influencia sobre la forma como se toman una gran cantidad de decisiones por parte de las plantas actuales y sobre todo sobre los cálculos financieros que por ello tienen que hacer los inversionistas, las decisiones de inversión y consumo. Modifica o lleva a la necesidad de cambios en el marco normativo del sector eléctrico y en las competencias que podrían tener las organizaciones del sector eléctrico.

d. Potencial de generación eléctrica de Costa Rica (PGECR): Es una variable que determina el potencial crecimiento de la oferta, las características de esta en cuanto a estacionalidad, energía firme, lugar de ubicación, necesidades de transmisión, esto repercute en que se puedan dar las pérdidas de electricidad, así como los costos de producción. Todo lo anterior determinado por factores concretos de carácter físico y técnico independientemente de otros condicionantes internos o externos al sector eléctrico. Esto hace que una variable que quizás no haya tenido importancia anteriormente, al integrar los efectos indirectos y el futuro tome relevancia en el sistema bajo estudio.

e. Influencia política en las decisiones (IPD): Una variable de carácter político que sigue teniendo vigencia futura. Esto fue planteado por los diferentes actores sociales conocedores del sector eléctrico a los cuales se les realizó entrevista o encuesta. (Jiménez 2009) Destaca el hecho de que pese a que el mercado sería el orientador, existen normas, directrices y reglas del juego que tienen influencia política, pues pueden definir la distribución de los ingresos del sector entre diferentes actores sociales.

Los números representan el orden de influencia o dependencia, según se desprende del Cuadro 11.

En el plano de la figura 12 se aprecia que un importante número de variables al considerar el futuro y los efectos directos e indirectos, pasan al sector 4 de variables excluidas (poco motrices y poco dependientes) y variables de resultado en el sector 3 (poco motrices, muy poco dependientes).

El sector 1 en donde se ubicarían las variables motrices y poco dependientes, no muestra ninguna variable, concentrándose las más relevantes en el plano de la figura 12, en donde se localizan las variables de enlace (variables muy motrices y muy dependientes). La ubicación de variables como MMN, GDO, CPE, TRSE, MIX y TSE, confirman lo expuesto previamente

El cuadro 12 permite establecer los siguientes aspectos de interés:

1. Establece las variables esenciales obtenidas a partir del análisis estructural, que serán necesarias para el análisis morfológico y específicamente la elaboración de escenarios.

2. Permite vincular las variables esenciales con los actores sociales de la red de políticas públicas que tienen más posibilidad de influencia directa.

3. Establece las formas en que los actores sociales de forma indirecta por medio de actores de relevo sugeridos, tratan de influir sobre las variables esenciales del sistema estudiado.

4. Sugiere formas de ejercer el poder, la influencia y explica comportamientos de los actores sociales. 
CUADRO 11

Resumen de las variables más importantes de la Matriz de Influencias Indirectas Potenciales (MIIP)

\begin{tabular}{|c|c|c|c|c|c|}
\hline \multirow{2}{*}{$\begin{array}{l}\text { Nombre } \\
\text { corto }\end{array}$} & \multirow{2}{*}{ Número y nombre de la variable } & \multicolumn{2}{|c|}{ Total } & \multicolumn{2}{|c|}{ Orden importancia } \\
\hline & & $\begin{array}{l}\text { Influencia } \\
\%\end{array}$ & $\begin{array}{l}\text { Dependencia } \\
\%\end{array}$ & Influencia & Dependencia \\
\hline SSE & 28 : Seguridad de suministro eléctrico & 2,7894 & 4,4584 & - & 1 \\
\hline CMS & $\begin{array}{l}14 \text { : Capacidad de movilización social y otros medio } \\
\text { legítimos para incidir en las políticas públicas }\end{array}$ & 2,0434 & 4,1999 & - & 2 \\
\hline TSE & 23 : Tarifas servicios eléctricos & 3,2153 & 4,1349 & 5 & 3 \\
\hline OE & 20 : Oferta de electricidad & 1,6539 & 4,0689 & - & 4 \\
\hline CIGTD & $\begin{array}{l}29: \text { Criterios para determinar inversiones en } \\
\text { generación, transmisión y distribución }\end{array}$ & 2,6565 & 3,8642 & - & 5 \\
\hline PE & 19 : Precio de la electricidad & 1,8989 & 3,5658 & 10 & 6 \\
\hline OAS & 43 : Objetivos de los actores sociales & 2,8368 & 3,4537 & - & 7 \\
\hline POS & $\begin{array}{l}42 \text { : Percepción e importancia de organizaciones en } \\
\text { la sociedad }\end{array}$ & 2,3693 & 3,3209 & - & 8 \\
\hline PAMR & 27 : Participación de actores en el mercado regional & 1,5845 & 3,2183 & - & 9 \\
\hline MMN & 24 : Mercado mayorista nacional & 4,9122 & 2,7950 & 1 & 10 \\
\hline GDO & 37: Grado de disociación de las organizaciones. & 4,2505 & 2,8410 & 2 & - \\
\hline CPE & 22 : Competencia en la producción de electricidad & 3,8104 & 2,6965 & 3 & - \\
\hline TRSE & 38: Tipo de regulación en el SE. & 3,6993 & 2,8251 & 4 & - \\
\hline PRE & 3: Política de regulación de la economía. & 3,1077 & 1,7307 & 6 & - \\
\hline MIX & $\begin{array}{l}30 \text { : Características y combinación de las fuentes de } \\
\text { generación del sector eléctrico (Mix) }\end{array}$ & 3,0607 & 2,8266 & 7 & - \\
\hline PGECR & 44 : Potencial de generación eléctrica de Costa Rica & 2,9865 & 2,0110 & 8 & - \\
\hline IPD & $\begin{array}{l}\text { 40: Influencia política en toma de decisiones } \\
\text { técnicas. }\end{array}$ & 2,8489 & 1,7325 & 9 & - \\
\hline
\end{tabular}

Fuente: Jiménez 2009.

La información obtenida del análisis estructural según las variables básicas y una primera aproximación de los actores que sobre ellas tienen influencia, así como el análisis realizado brindan insumos para el análisis de los actores sociales de la red de políticas públicas, en el estudio de Jiménez (2009).

\section{DISCUSIÓN}

Del análisis estructural en el sector eléctrico

De forma específica el análisis estructural permitió establecer las variables externas e internas que bajo la concepción asumida en esta investigación se consideran 


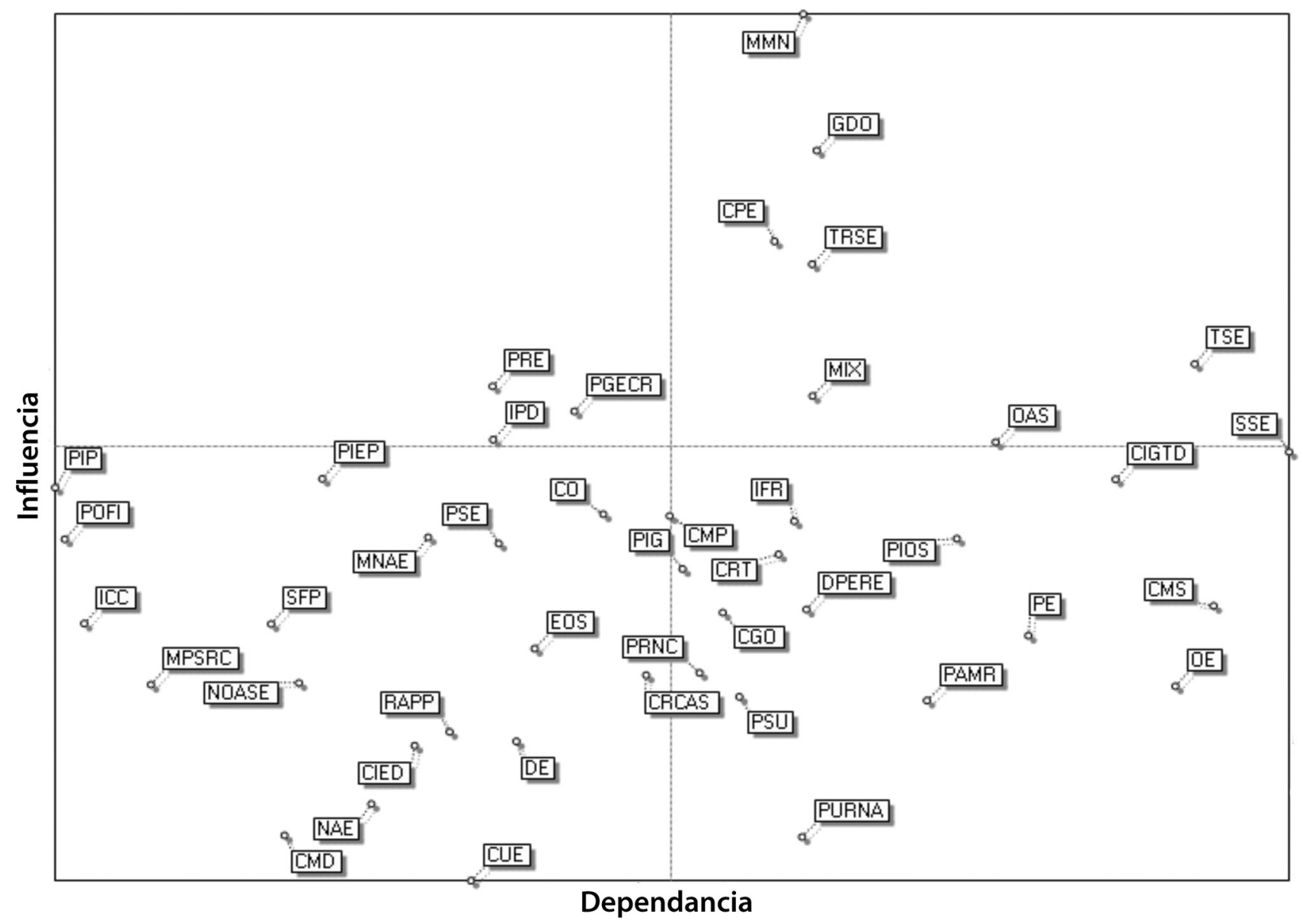

FIG. 7. Plano de influencias/dependencias indirectas potenciales. Fuente: Jiménez 2009.

relevantes. Se aprecia por su parte, que dependiendo del marco teórico es posible que un mismo sistema de análisis tenga diferentes variables relevantes, pues precisamente los conceptos y categorías, definidos en un determinado marco teórico, llevan a especificar o desechar aspectos que son considerados o dejados de lado a la hora de definir las variables importantes del sistema en estudio.

En el caso de la presente investigación, el análisis estructural realizado trató de identificar y considerar todas aquellas variables que fueran sustantivas en la definición y explicación del sistema eléctrico de Costa Rica, considerando desde una perspectiva amplia aspectos físicos, técnicos, socioculturales, políticos y económicos. Los procesos de depuración y ajuste llevaron a establecer un conjunto de variables, las cuales fueron conceptualizadas partiendo del objeto de estudio de la investigación y de las convenciones existentes.

Predominan en las variables externas relevantes seleccionadas las económicas y sociopolíticas. Las económicas refieren en forma general a los aspectos que definen el modelo económico que oriente el país y que sin duda determina en mucho las posibles orientaciones que en el seno del sector eléctrico se presenten. Además de la actividad económica, el sector eléctrico ha sido altamente influenciado y lo será en el futuro en el contexto de la reforma por las políticas de inversión y de gasto público de los gobiernos, así como por la política de regulación de la economía que incidiría en el diseño probable de la reforma del sector eléctrico.

En el marco de una potencial reforma neoclásica del sector eléctrico las variables más relevantes establecidas fueron: Mercado mayorista nacional, Grado de disociación de las organizaciones del sector eléctrico, Competencia en la producción de electricidad, Influencia política en las decisiones, Potencial de generación eléctrica de Costa Rica

Desde el punto de vista sociopolítico resalta en las variables externas seleccionadas la importancia que tienen los mecanismos de participación social y rendición de cuentas a los ciudadanos, así como la capacidad de movilización social y otros recursos de la sociedad para incidir sobre las políticas públicas. En general pareciera claro que de acuerdo a la correlación de fuerzas políticas que 


\section{CUADRO 12}

Variables esenciales seleccionadas y los actores sociales asociados

\begin{tabular}{|c|c|c|}
\hline $\begin{array}{c}\text { Número y nombre de las variables } \\
\text { relevantes }\end{array}$ & $\begin{array}{l}\text { Actores con influencia } \\
\text { Directa }\end{array}$ & Actores relevo \\
\hline 2: Política de inversión y de gasto público & \multirow{2}{*}{$\begin{array}{l}\text { Presidencia de la República, Asamblea } \\
\text { Legislativa }\end{array}$} & $\begin{array}{l}\text { Ministerio de Hacienda, Banco Central, Ministerio de } \\
\text { Planificación. }\end{array}$ \\
\hline 3: Política de regulación de la economía. & & $\begin{array}{l}\text { Ministerios de: Economía, Ambiente, Salud y } \\
\text { Hacienda }\end{array}$ \\
\hline $\begin{array}{l}\text { 6: Políticas y acciones de los organismos } \\
\text { financieros internacionales con respecto a la } \\
\text { participación pública en la economía }\end{array}$ & $\begin{array}{l}\text { Presidencia de la República, Ministerio } \\
\text { de Hacienda, Banco Central }\end{array}$ & $\begin{array}{l}\text { Organizaciones que acceden a los créditos y } \\
\text { ejecutan las disposiciones. }\end{array}$ \\
\hline $\begin{array}{l}\text { 8: Precio internacional de los derivados del } \\
\text { petróleo. }\end{array}$ & $\begin{array}{l}\text { Mercados internacionales, Organización } \\
\text { de Productores de Petróleo }\end{array}$ & RECOPE, ARESEP \\
\hline $\begin{array}{l}\text { 10: Dotación y posibilidad de explotación } \\
\text { de recursos energéticos. }\end{array}$ & $\begin{array}{l}\text { Determinados de forma natural } \\
\text { (dotación) Asamblea Legislativa. }\end{array}$ & $\begin{array}{l}\text { MINAE, ICE } \\
\text { Empresas privadas }\end{array}$ \\
\hline $\begin{array}{l}14 \text { : Capacidad de movilización social y } \\
\text { otros medios legítimos para incidir en las } \\
\text { políticas públicas }\end{array}$ & $\begin{array}{l}\text { Organizaciones sociales y ambientales. } \\
\text { Sindicatos. } \\
\text { Estudiantes universitarios. }\end{array}$ & Dirigentes de las diferentes organizaciones. \\
\hline \multirow{2}{*}{19 : Precio de la electricidad } & $\begin{array}{l}\text { Asamblea Legislativa al definir tipo de } \\
\text { regulación. }\end{array}$ & Ente encargado según diseño modelo eléctrico. \\
\hline & Poder Ejecutivo. & ARESEP \\
\hline 20 : Oferta de electricidad & \multirow{5}{*}{$\begin{array}{l}\text { Presidencia de la República, Asamblea } \\
\text { Legislativa con base en marco } \\
\text { institucional, según reglas y criterios } \\
\text { para inversión y operación. }\end{array}$} & \multirow{2}{*}{$\begin{array}{l}\text { Organizaciones participantes. Entes operadores del } \\
\text { sistema y de regulación. }\end{array}$} \\
\hline $\begin{array}{l}22: \text { Competencia en la producción de } \\
\text { electricidad }\end{array}$ & & \\
\hline 23 : Tarifas servicios eléctricos & & ARESEP \\
\hline 24 : Mercado mayorista nacional & & \multirow{2}{*}{$\begin{array}{l}\text { Entes operadores del sistema y de regulación } \\
\text { nacional. Forma de integración al mercado eléctrico } \\
\text { regional. }\end{array}$} \\
\hline $\begin{array}{l}\text { 27: Participación de actores en el mercado } \\
\text { regional }\end{array}$ & & \\
\hline 28 : Seguridad de suministro eléctrico & MINAE & Organizaciones del sector. \\
\hline $\begin{array}{l}\text { 29: Criterios para determinar inversiones en } \\
\text { generación, transmisión y distribución }\end{array}$ & $\begin{array}{l}\text { Presidencia de la República } \\
\text { Asamblea Legislativa }\end{array}$ & MINAE, ARESEP \\
\hline $\begin{array}{l}\text { 30: Características y combinación de las } \\
\text { fuentes de generación del sector eléctrico } \\
\text { (Mix) }\end{array}$ & $\begin{array}{l}\text { Características físicas del país. } \\
\text { Organizaciones existentes }\end{array}$ & $\begin{array}{l}\text { Entes operadores del sistema y de regulación. } \\
\text { Organizaciones del sector. }\end{array}$ \\
\hline $\begin{array}{l}\text { 37: Grado de disociación de las } \\
\text { organizaciones. }\end{array}$ & $\begin{array}{l}\text { Asamblea Legislativa } \\
\text { Presidencia de la República }\end{array}$ & MINAE \\
\hline 38: Tipo de regulación en el SE. & \multirow{2}{*}{$\begin{array}{l}\text { Asamblea Legislativa y Presidencia de la } \\
\text { República al definir tipo de regulación. }\end{array}$} & \multirow{2}{*}{$\begin{array}{l}\text { MINAE, ARESEP. Entes operadores del sistema y de } \\
\text { regulación }\end{array}$} \\
\hline 39: Incentivos para fuentes renovables. & & \\
\hline $\begin{array}{l}\text { 40: Influencia política en toma de decisiones } \\
\text { técnicas. }\end{array}$ & $\begin{array}{l}\text { Diputados, Ministros y Presidencia del } \\
\text { República }\end{array}$ & $\begin{array}{l}\text { Presidentes Ejecutivos, miembros de Juntas } \\
\text { Directivas, Regulador, Contralor, Ministros, } \\
\text { funcionarios públicos. }\end{array}$ \\
\hline $\begin{array}{l}\text { 42: Percepción e importancia de } \\
\text { organizaciones en la sociedad }\end{array}$ & Organizaciones del sector. & Instituciones y empresas existentes \\
\hline 43 : Objetivos de los actores sociales & $\begin{array}{l}\text { Presidencia de la República, Asamblea } \\
\text { Legislativa con base en marco } \\
\text { institucional, según reglas y criterios } \\
\text { para inversión y operación }\end{array}$ & $\begin{array}{l}\text { Organizaciones del sector. Consumidores. } \\
\text { Ciudadanos }\end{array}$ \\
\hline $\begin{array}{l}44 \text { : Potencial de generación eléctrica de } \\
\text { Costa Rica }\end{array}$ & Determinados naturalmente & Organizaciones del sector. \\
\hline
\end{tabular}

Fuente: Jiménez 2009 
tienen el poder en el país, es muy posible que reformas de corte neoclásico puedan llevarse a cabo, sin embargo, en general el elemento que inhibe y el cuidado que media en las propuestas y su posibilidad de ejecución estriba en la probabilidad de que se desencadenen procesos de movilización social similares a los que se dieron en 1963, 1983 y 2000 que puedan dar al traste con las reformas y con la capacidad política misma del gobierno. Por ello, la variable "Capacidad de movilización social" es importante, aunque en ciertos momentos pareciera no serlo, ciertos contextos y propuestas pueden desencadenar en la sociedad costarricense movimientos sociales de alcance poco previsible.

Las variables "costumbres y reglas de comportamiento de los actores sociales", "capacidad de gestión de las organizaciones" y "respeto y aplicación de las normativas y políticas públicas", son variables consideradas que tienen una influencia neoinstitucionalista. Estas influyen de forma no siempre perceptible por el sistema, pero en el marco de la reforma del sector eléctrico, cuando se propongan determinadas opciones de reforma incidirán en las posibles acciones y comportamientos de los actores sociales y por ende en los resultados.

Las variables internas relevantes del sistema eléctrico consideradas en el análisis están clasificadas en económicas, institucionales, socioeconómicas y físicas. Implícitamente en la mayoría de variables se debe tener presente aspectos técnicos operativos de los sistemas eléctricos que determinan o limitan la forma cómo debe operar el sistema.

Para el análisis estructural se establecieron las variables esenciales del sistema, las cuales fueron establecidas con base en el análisis de los procesos de reforma internacional, las propuestas realizadas en el país, los objetivos y criterios de los actores sociales y las orientaciones fundamentales del sistema (la situación actual y las posibilidades futuras). De los resultados obtenidos se aprecia que hay variables claves que en el marco de una posible reforma desencadenan procesos de cambio en todos los ámbitos. Este es el caso de variables como: "competencia en la producción de electricidad", "mercado mayorista nacional", "participación de actores en el mercado regional", estas variables están relacionadas con procesos de apertura y creación de un mercado en el sector eléctrico. La participación en el mercado regional parte del supuesto de que la red física de transmisión y las reglas del juego que surjan estimularán la realización de transacciones de los actores calificados para ello.

Dentro de las variables relevantes analizadas prevalecen las de tipo económico; sin embargo, resaltan algunas sociopolíticas como la influencia política en las decisiones, algo que evidencia la debilidad institucional del sistema.
Igualmente resultó relevante la "percepción e importancia de las organizaciones en la sociedad", que denota el valor de éstas. Otras variables relevantes que se ha indicado que fueron consideradas fueron la "capacidad de movilización social". Las variables más relevantes están asociadas a los aspectos económicos que forman parte de la agenda de reforma del sector eléctrico, como se mencionó al inicio, asociadas a la creación y ampliación del mercado eléctrico en el ámbito regional, pero a su vez surgen contrapesos en variables como la valoración positiva de las organizaciones del sector y la posibilidad de movilización social que hace que los promotores de reformas neoclásicas sean un poco más cautos.

\section{Conclusiones sobre aspectos metodológicos}

En la investigación realizada el proceso de definición de las variables en la matriz respectiva y su análisis de sensibilidad y discusión con profesionales del sector fue una de las labores más intensas y que requirió de mayor tiempo y atención.

Del proceso realizado se puede indicar que ayudó a poder establecer los aspectos que más incidencia tienen y podían tener en el funcionamiento del sistema bajo estudio: el sector eléctrico y sus determinantes internos y externos. La necesidad de seleccionar, filtrar y escoger con base en el análisis de las relaciones lógicas, el grado de influencia relativa y la discusión con profesionales del sector permitió una mejor comprensión de los elementos que determinan al sector eléctrico y dentro de él sus variables sustantivas. Queda claro también que la concepción teórica del analista define en mucho las variables que sean consideradas. En el caso de esta investigación se aprecia que en la definición de algunas variables y en su selección hay una influencia del enfoque teórico neoinstitucionalista.

Un elemento importante de considerar es que en el proceso de selección de variables del análisis estructural y en el establecimiento de sus relaciones lógicas es posible tener un espacio de encuentro entre diferentes disciplinas científicas, dando lugar a un efectivo análisis multidisciplinario, mediante la integración de variables técnicas, económicas, sociales y políticas.

Las variables esenciales seleccionadas son un insumo básico establecer los actores sociales de la red de políticas públicas, derivado de la definición de los retos estratégicos, las aspiraciones, los objetivos asociados y la asignación de recursos para poder incidir, así como la viabilidad de acuerdos y alianzas entre éstos está explicado y a su vez incide en las variables que se han seleccionado mediante el método de análisis estructural. 


\section{REFERENCIAS}

Bacon, R. \& J. Besants. 2001. Global electric power reform, privatization, and liberalization of the electric power industry in developing countries. Annual Reviews Energy \& The Enviroment 26:331-359.

Bazán, C. 2003. Efectos de la reforma del sector eléctrico: Modelización teórica y experiencia internacional. Tesis para optar por el grado de Doctorado en Economía: Universidad de las Palmas de Gran Canaria, España.

Besants, J. 2006. Reforming Power Markets in Developing Countries: What have we learned? The World Bank, Washington D.C., EEUU.

Besant, J. \& Tenenbaum, B. 2001. Enseñanzas de la crisis de energía de California. Revista Finanzas y Desarrollo 38:24-30.

CEPAL, 2004. Estrategia para el fomento de las fuentes renovables de energía en América Central. Naciones Unidas Comisión Económica para América Latina y el Caribe, México DF, México.

Del Toro, W. 2004. Modelo de simulación prospectiva de la demanda de servicios de salud para enfermedades de alto costo: aplicación para una entidad promotora de salud colombiana. Departamento de economía y ciencias sociales. Universidad Politécnica de Valencia, España.

Dussán, M. 2004. Nicaragua: Opciones de política para la reforma del sector eléctrico. Informe técnico. Departamento de desarrollo sostenible. Banco Interamericano de Desarrollo. Nueva York, EEUU.

Estache, A. 2002. Cómo hacer que las reformas de la infraestructura en América Latina favorezcan a los pobres. Revista CEPAL 78:105-124.

Godet, M. 2007. La caja de herramientas de la prospectiva estratégica. Laboratorio de investigación en prospectiva estratégica. Prospektiker, San Sebastián, Guipúzcoa, España.

Hunt, S. \& G. Shuttlesworth. 1996. Competition and choice in electricity. John Wiley \& Sons, New York, EEUU.

Jiménez, R. 2009. Análisis del proceso de formulación de políticas para la reforma del sector eléctrico y su potencial incidencia en el marco institucional y la producción con fuentes renovables. Tesis sometida a la consideración de la Comisión del Programa de Estudios de Posgrado en Gobierno y Políticas Públicas para optar al grado de Doctor en Gobierno y Políticas Públicas, Universidad de Costa Rica, San José, Costa Rica.

Jamasb, T. 2006. Between the state and market: Electricity sector reform in developing countries. Faculty of Economics, University of Cambridge, Cambridge, United Kingdom.

Medina, J. \& E. Ortegón. 2006. Manual de prospectiva y decisión estratégica: bases teóricas e instrumentos para América Latina y el Caribe. ILPE-CEAPAL, Santiago, Chile.

Millán, J. 2006. Entre el mercado y el Estado: Tres décadas de reformas en el sector eléctrico de América Latina. Banco Internacional de Desarrollo, New York, EEUU.

Mojica, F. 2006. La construcción del futuro: Concepto y modelo de prospectiva estratégica, territorial y tecnológica. Universidad Externado de Colombia, Convenio Andrés Bello. Bogotá, Colombia.

North, D. 2005. Institututions, Institucional change and economic perfomance. Cambridge University, Cambridge, United Kingdom.

Pollitt, M. 2005. Electricity Reform in Chile: Lessons for Developing Countries. Massachusetts Institute of Technology, Center for Energy and Environmental Policy Research. Massachusetts, EEUU. 


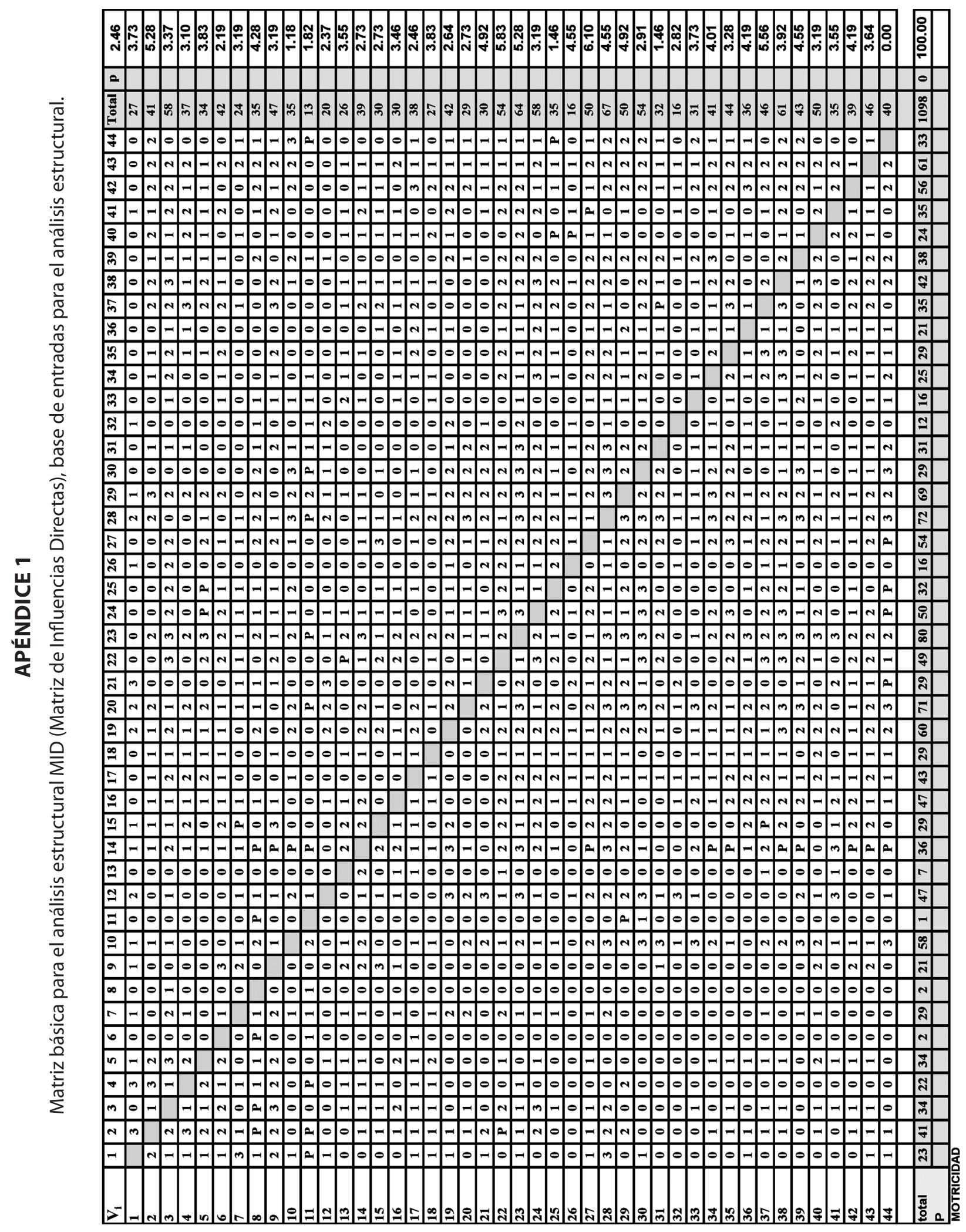

